\title{
CONDICIONES PALEOVEGETACIONALES Y ASENTAMIENTOS HUMANOS DURANTE EL FORMATIVO TEMPRANO: ANÁLISIS DE POLEN DEL SITIO TULÁN-85 (1.530/1.260-460/420 AÑOS CAL. A.C.), CUENCA DEL SALAR DE ATACAMA
}

\author{
PALEOVEGETATION CONDITIONS AND HUMAN SETTLEMENTS DURING \\ THE EARLY FORMATIVE: POLLEN ANALYSIS FROM THE TULÁN-85 SITE \\ $(1,530 / 1,260-460 / 420$ CAL. YR. BC), IN THE SALAR DE ATACAMA BASIN
}

\author{
Leticia González-Silvestre ${ }^{1}$, Antonio Maldonado ${ }^{1,2,3}$, Lautaro Núñez ${ }^{4}$, \\ Isabel Cartajena ${ }^{5}$, Carlos Carrasco ${ }^{6}$ y Patricio de Souza ${ }^{6}$
}

\begin{abstract}
Se presenta el análisis polínico obtenido de una columna estratigráfica que cubre toda la secuencia ocupacional del asentamiento formativo temprano Tulán-85 localizado al sureste del salar de Atacama fechado entre los 1.530-1.260 a 460-420 cal. a.C. Se concluye que es posible diferenciar mediante el polen actual tres pisos altitudinales de vegetación, al tanto que la comparación de las muestras fósiles con aquellas actuales sugieren condiciones de mayor humedad en la base de la secuencia, al comienzo de la fase Tilocalar (1.530-1.260 cal. a.C.). En los niveles medios comienzan los eventos áridos, identificándose al final de la columna los mayores indicadores de aridez. Los antecedentes paleoclimáticos de la alta puna señalan que las ocupaciones pastoralistas de la fase Tilocalar son sincrónicas con el establecimiento de condiciones más húmedas, lo que es concordante con los resultados del análisis polínico. Estas habrían repercutido favorablemente en las ocupaciones pastoralistas en los pisos inferiores. Es importante destacar la identificación de eventos de aridez hacia el final de la ocupación, los que no habían sido descritos con anterioridad para el área de estudio.
\end{abstract}

Palabras claves: Formativo Temprano, polen fósil, condiciones húmedas, eventos áridos, salar de Atacama.

Pollen analysis from a stratigraphic column that represents the entire temporal occupation of the Early Formative Tulán-85 site is presented. The site is located at the southeast border of the Salar de Atacama, and dates to between 1,530-1,260 to 460-420 cal $B C$. By using a comparison with modern pollen we were able to differentiate three altitudinal vegetation levels. This comparison suggests there existed more humid conditions at the beginning of the Tilocar phase (1,530-1,260 cal. BC). In the middle of the sequence arid events were detected, showing an increasing aridity toward the upper end of the stratigraphic column. Results of the pollen analysis match paleoclimatic information from the high Puna suggesting the synchronicity between a more favorable humid phase with the establishment of pastoralist settlements located at lower elevations. It is also important to denote the identification of arid events at the end of the occupational sequence, which were not described before for this area.

Key words: Early Formative, pollen, humid conditions, arid events, Salar de Atacama Basin.

Hay consenso que existe una cerrada relación entre las ocupaciones humanas y las condiciones paleoambientales variables en términos de impactos favorables o limitantes. Durante el Holoceno las poblaciones asentadas en la región Circumtiticaca se vieron afectadas por cambios paleoclimáticos reflejados a través de la fluctuación de los niveles paleolacustres (Abbott et al. 2003; Binford 1997). Por otra parte, en los Andes circumpuneños se han identificado estas variaciones y su impacto en los grupos humanos localizados en la vertiente occidental de la puna de Atacama (Grosjean et al. 2003; Latorre et al. 2002; Maldonado y Rozas 2008; Núñez et al. 2010). En relación con el área

\footnotetext{
Centro de Estudios Avanzados en Zonas Áridas, La Serena, Chile. leticia.gonzalez@ceaza.cl

Universidad de La Serena, La Serena, Chile. amaldona@userena.cl

Departamento de Biología Marina, Universidad Católica del Norte, Coquimbo, Chile.

4 Instituto de Investigaciones Arqueológicas y Museo, Universidad Católica del Norte, San Pedro de Atacama, Chile.

lautaro.nunez@hotmail.com

5 Departamento de Antropología, Universidad de Chile, Santiago, Chile. icartaje@uchile.cl

6 Colegio de Arqueólogos AG, Santiago, Chile. carrcag@gmail.com; desouza.herreros@gmail.com
} 
de estudio, los resultados del análisis de columnas sedimentológicas y de polen realizados en la laguna Miscanti (4.250 msm), ubicada a $55 \mathrm{~km}$ de los sitios de la fase Tilocalar, en el borde oriental del salar de Atacama, señalan la vigencia de un Holoceno Medio árido entre los ca. 6.000-1.200 cal. a.C. La aridez prolongada provocó un fuerte impacto en las ocupaciones humanas estimulándose ya sea la migración o la concentración de las poblaciones arcaicas-formativas en ecorrefugios locales entre los ca. 2.800 y 1.200 cal. a.C. (Grosjean y Núñez 1994; Grosjean et al. 2001; Messerli et al. 2000; Núñez et al. 1997; Núñez, Grosjean y Cartajena 1999; Núñez et al. 2001, 2002). El retorno del régimen húmedo, similar a las condiciones actuales, habría ocurrido a los 1.200 cal. a.C. a lo largo de un escenario regional, como se advierte también a unos $460 \mathrm{~km}$ al sur de Miscanti, en la laguna altoandina Negro Francisco, donde las condiciones favorables se habrían iniciado al mismo tiempo (Grosjean et al. 1997). Este fenómeno se observa también hacia el norte, en la puna seca, donde se incrementa la humedad en relación con el período anterior (Gayó et al. 2012).

En principio, los espacios circumpuneños se habían considerado como hábitats estables, debido a la falta de secuencias paleoclimáticas y vegetacionales, donde hasta hace poco tiempo la mayoría de las reconstrucciones paleoambientales se realizaban a partir de evidencias indirectas o con extrapolaciones de secuencias obtenidas para espacios no siempre aledaños. Sin embargo, en los últimos años en la Puna de Atacama los estudios referidos han generado las primeras reconstituciones paleoambientales asociadas a poblamientos humanos específicos (Betancourt et al. 2000; Bobst et al. 2001; Núñez et al.1997; Núñez et al. 2001).

La incorporación de nuevas líneas de evidencias como los análisis de restos vegetales en depósitos fósiles de roedores y de paleohumedales obtenidos en lugares muy cercanos a los sitios arqueológicos, han demostrado, por otra parte, un incremento de las precipitaciones estivales en la cobertura de pastos y en los niveles de agua subterránea entre ca. 14.200 y ca. 8.500 cal. a.C. (Betancourt et al. 2000). Tanto los arbustos propios de las elevaciones más altas como aquellos pastos de florecimiento estival se expandieron a lo largo de laderas que en la actualidad corresponden al borde del desierto absoluto. El periodo más húmedo correspondería a ca. 9.800 - ca. 8.500 cal. a.C. Algunas especies vegetales descendieron hasta $1.000 \mathrm{~m}$, lo que reflejaría un aumento significativo de las precipitaciones. Contrariamente, entre ca. 6.500 y 6.300 cal. a.C. los depósitos fósiles reflejan una aridez abrupta, mientras que entre ca. 3.100 cal. a.C. y ca. 100 cal. d.C. se observa una composición vegetal similar a la actual, pero con una mayor diversidad correspondiente a un periodo húmedo. Después de ca. 1.000 cal. a.C. se establecería el clima actual con marcadores de aridez (Betancourt et al. 2000). Recién entre ca. 1.400-1.200 cal. d.C. el polen da cuenta de un intervalo húmedo inusual, que podría estar asociado a un periodo de inviernos húmedos (Maldonado et al. 2005). Sin embargo, otras investigaciones multidisciplinarias basadas en otros proxies indican que a partir de ca. 1.000 cal. a.C. recién se habría recuperado el régimen de humedad (Grosjean et al. 2001; 2003).

No obstante, si bien se encuentran bien documentadas las condiciones paleoclimáticas que prevalecieron durante el Holoceno Medio y Tardío, poco se conoce acerca del impacto que habría tenido la reactivación de un régimen más húmedo que el actual para los grupos humanos asentados en las tierras más bajas del borde sureste de la cuenca del salar de Atacama. Con este fin se analiza la evidencia polínica procedente del asentamiento Tulán-85 localizado en el piso de vegetación inferior y asociado a las vegas situadas en el borde oriental del salar de Atacama.

El retorno de condiciones más húmedas durante el Holoceno Tardío a lo largo de una amplia escala macrorregional (Gayó et al. 2012; Núñez et al. 2002), es coincidente con el incremento de las instalaciones humanas durante el Formativo Temprano del transecto Tulán (Figura 1), asociadas a prácticas dominantes de caza y crianza de camélidos relacionadas con recursos forrajeros óptimos, en sincronía con otros asentamientos complejos localizados en las tierras altas del Centro Sur andino (López et al. 2013; Núñez y Santoro 2011; Núñez et al. 2002, 2006). En este sentido, los análisis interdisciplinarios derivados del amplio espectro geográfico requieren incorporar también otros estudios de carácter microespaciales orientados a evaluar estas variaciones en secuencias locales con enfoques complementarios, que en este caso se orientan a identificar a través del polen posibles fluctuaciones de eventos áridos y húmedos, en un asentamiento característico de la Fase Tilocalar (Tulán-85).

El Formativo Temprano en la región de estudio se encuentra caracterizado por la fase Tilocalar identificada al sureste de la Cuenca del Salar de 


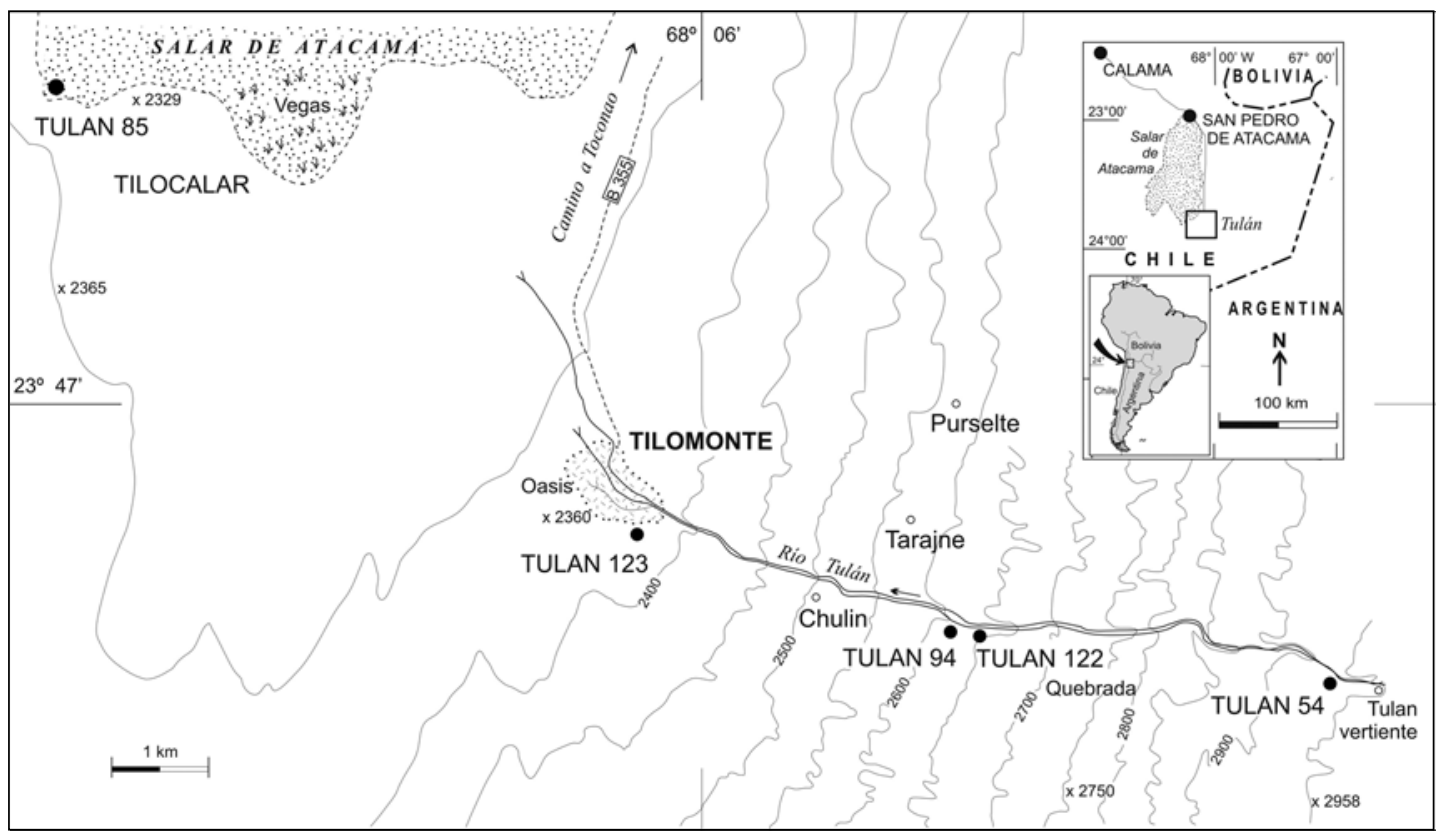

Figura 1. El transecto Tulán y la ubicación de los sitios formativos tempranos de la fase Tilocalar. La flecha indica la ubicación del sitio Tulán-85.

Tulán transect and location of early formative sites of Tilocalar phase. The arrow indicates the location of the Tulán-85 site.

Atacama. En este lugar se encuentran tres grandes asentamientos sincrónicos dispuestos en la quebrada de Tulán (Tulán 54 y 122) y en el borde del salar (Tulán-85). Los tres asentamientos del transecto Tulán sugieren el desarrollo de un modelo de asentamientos complementarios entre sí, caracterizado por sus roles funcionalmente diferenciados (ceremonial, productivo y habitacional), dispuestos en espacios vinculantes de corta distancia entre las quebradas intermedias y las playas del salar, lo que permite la combinación de los logros derivados de la explotación ganadera, hortícola subsidiaria, de los recursos de vegas y prácticas de caza bajo una organización político-religiosa común.

En términos de arquitectura se registra una modalidad de construcción basada en la presencia de grandes recintos circulares aglomerados conformados por lajas verticales y bloques dispuestos en aparejo sedimentario sobre las primeras, pero con significativas diferencias de configuración y escala. Estas diferencias se manifiestan en recintos monumentales (Tu-54), estructuras habitacionales complejas (Tu-122) y otras aglutinadas más simples (Tu-85). En el sitio Tu-54 se identifican varios sectores que muestran una compleja organización del espacio, destacando un gran templete central, otra estructura de funcionalidad ritual de menor escala y estructuras muy rudimentarias alrededor vinculadas con ocupaciones habitacionales no permanentes. Este sitio se configuraría como un centro eminentemente ceremonial que concentra en cada uno de sus espacios actividades rituales, desarrollo de tareas artesanales y actividades de faenamiento y consumo de camélidos, orientados a acciones no domésticas. Por su parte, el sitio Tu-85 se caracteriza por la presencia de un montículo central de basuras, cuya parte más alta cubre un conjunto de estructuras aglomeradas, incluyendo una gran área de tareas y actividades múltiples, principalmente artesanales y de faenamiento, con presencia de actividades rituales en menor grado como aquellas inhumaciones de neonatos localizadas entre depósitos estratificados (Figura 2).

En efecto, el asentamiento Tu-85 se caracteriza por la presencia de un gran montículo central de basuras de hasta 2,40 metros de profundidad, resultantes de diversas actividades como manufactura y faenamiento, entre otras, desarrolladas en un espacio abierto sin estructuras asociadas. Los únicos recintos vinculados a estos depósitos se encuentran en el sector SE del asentamiento y que corresponden a construcciones habitacionales 


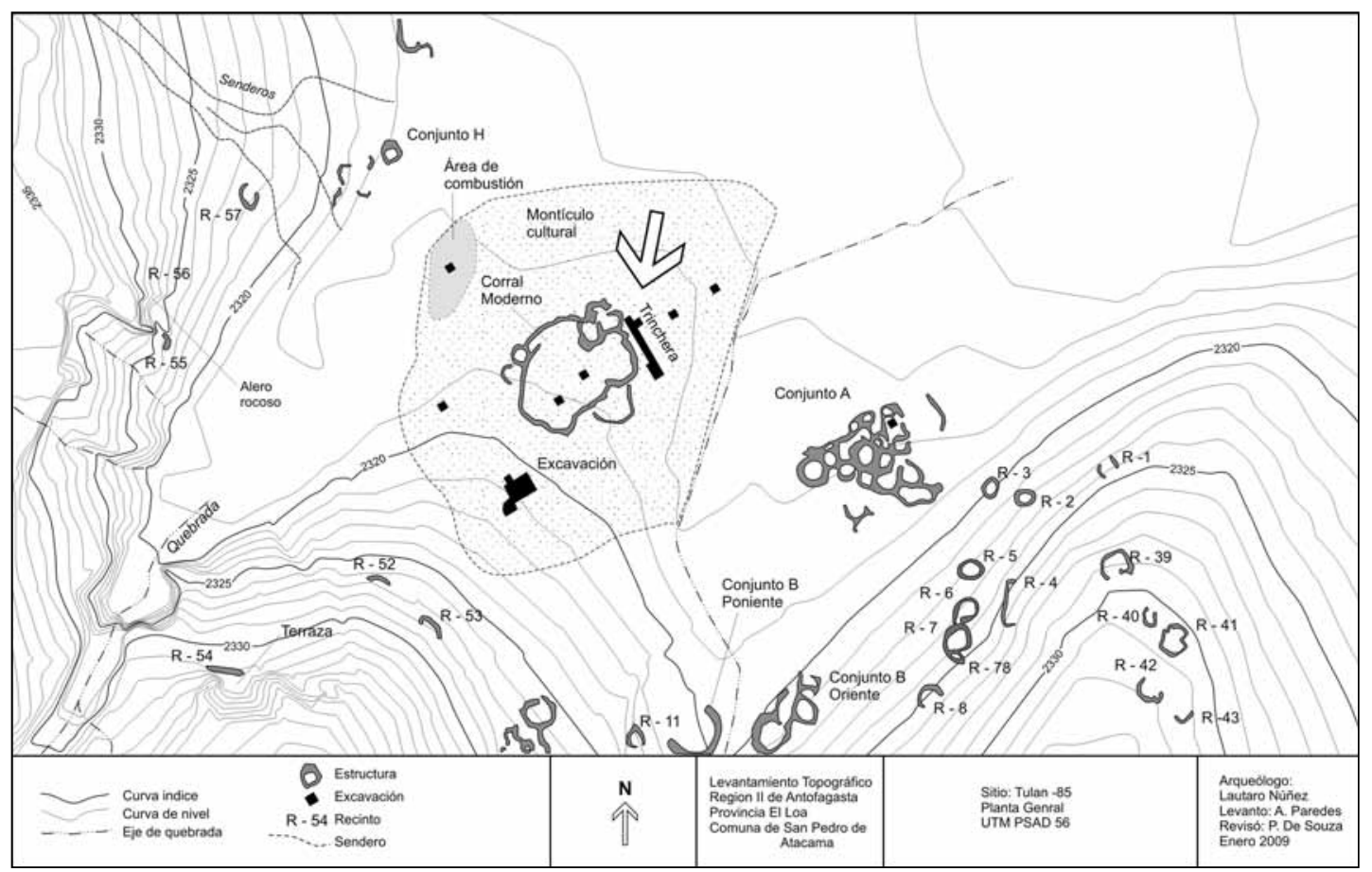

Figura 2. Plano del sitio Tulán-85. La flecha indica la locación de la columna de polen analizada y el perfil estratigráfico de procedencia (Paredes 2009).

Map of the Tulán-85 site. The arrow points to the location of the sedimentary sequence and pollen profile analyzed for the present paper (Paredes 2009).

de momentos finales de la fase Tilocalar. Si bien en este montículo no se observan espacios o estructuras destinados especialmente a actividades rituales, sólo se han registrado enterratorios de neonatos desde los inicios de ocupación hasta la mitad de los depósitos culturales en el centro del montículo, además de un solo caso en el piso de uno de los recintos localizados al oriente del sitio. Las tempranas dataciones en Tu- 85 desde los 1.530 cal. a.C. corresponden a los inicios de ocupación de los potentes basurales del centro del sitio, no asociados a estructuras, con ofrendas en depresiones socavadas en el piso inicial compuesta de cuentas de mineral de cobre y masa de arcilla pintada. Las ocupaciones más tardías pertenecientes a la fase Tilocalar se identificaron en un sector más alto, en estructuras residenciales circulares situadas bajo depósitos menos densos, datados a comienzos de ocupación a sólo $60 \mathrm{~cm}$ de profundidad, en el rango de 780 a 390 cal. a.C., estableciéndose una diferencia estimada de unos 500 años con respecto a las muestras antes referidas. Es decir, hasta esta época las comunidades Tilocalar habitaban en Tu-85, tal como se observa en las ultimas ocupaciones del montículo-basural con la datación superior del orden de los 790 a 490 cal. a.C. Por otro lado, se sabe que escasas agrupaciones posteriores a Tilocalar se instalaron en la superficie del montículo, donde prepararon fogones aislados a unos $30 \mathrm{~cm}$ de profundidad, datado entre los 1.020 a 1.200 cal. d.C. correspondiente al periodo de Desarrollo Regional. Estas evidencias indican que existen reocupaciones tardías, lo que explica que las capas altas presenten un patrón distinto de estratificación.

Los materiales recuperados en este asentamiento pueden ser considerados diagnósticos de la fase Tilocalar, como la cerámica Los Morros, abundantes perforadores, cuentas, mineral de cobre y láminas de toba Tulán, entre otros. En efecto, se registró una alta frecuencia de perforadores $(85,8 \%)$, lo que denota una producción intensiva de cuentas. Además, los restos malacológicos sugieren circulación tanto de materias primas como de cuentas desde el Pacífico y la vertiente oriental de los Andes. Los vegetales evidencian la recolección y utilización de especies locales, sin embargo, los escasos restos de cultivos y la carencia de espacios de arboledas sugieren que el cultivo y la recolección de frutos se realizaría en 
lugares más propicios como el oasis de Tilomonte o bien podrían ser de origen extralocal (p.ej. Lagenaria sp. y cf. Cucurbita sp.). El contexto es fundamentalmente doméstico orientado a la explotación local y del transecto Tulán, a juzgar por los recursos vegetales y faunísticos recuperados. Los artefactos líticos como cuchillos, raederas, cuñas y morteros permiten inferir actividades vinculadas al procesamiento de recursos locales varios, mientras que en la cerámica Los Morros se observa poca restaurabilidad con fragmentos más pequeños que dan cuenta más bien de depósitos domésticos.

La presencia significativa de restos óseos, vellones y la asociación del sitio a las vegas del salar de Atacama, sugiere una orientación productiva hacia la explotación de camélidos. Ciertamente, los resultados obtenidos a partir de los análisis de isótopos estables han permitido comprender el uso del espacio utilizado para el manejo de rebaños y áreas de caza (López et al. 2011). En el caso de los guanacos, estos habrían sido cazados tanto en zonas de quebradas altas como en el piso del salar. Lo mismo sucede con la explotación de los camélidos domésticos (llama), los que habrían tenido dos áreas de pastura, una ubicada en cotas altas y una segunda en las vegas del salar de Atacama. Es interesante notar que tanto en los sitios Tu-54 como Tu-85 se encuentran animales tanto domésticos como silvestres provenientes de ambos microambientes, lo que señala que ambos sitios serían lugares de convergencia para las poblaciones de pastores-cazadores que se movían por el transecto Tulán. Así, mientras los restos de huevos y huesos de parinas evidencian ocupaciones estivales, los restos óseos de camélidos sugieren que en esta estación la explotación de camélidos no se concentraría en Tu-85, por lo que cabría suponer que ciertos grupos se trasladarían a cotas más altas para actividades de pastoreo, complementarias al forraje de las vegas del salar.

Se ha evidenciado una alta frecuencia de artefactos de hueso que estarían destinados al trabajo en lana, cuero y cestería, lo que al parecer sería generalizado (Santander 2010; Santander 2011). En este sentido la presencia de vellones asociados a los instrumentos de hueso sugiere la posibilidad de una producción de textiles o hilados. Lo anterior es especialmente evidente en el montículo Tu-85, que ha sido interpretado como una gran área de trabajo, en donde además de lo anterior se desarrollarían actividades de faenamiento posiblemente relacionado con la producción de charqui y esquila.
De existir una relación entre la concentración de asentamientos y la reactivación de un régimen húmedo, debería esperarse en el registro polínico taxas propias de un régimen de humedad equivalente a un foco atractivo que pudo mantenerse a través de toda la secuencia. Sin embargo, ¿cuál es la causa para que tardíamente se abandone el yacimiento?, ¿la secuencia polínica podría explicar posibles eventos de estabilidad versus determinadas crisis ambientales que habrían estimulado el cambio del asentamiento?, ¿fueron decisiones culturales mixtas y/o independientes de las fluctuaciones paleoambientales?

\section{El Marco Fisiográfico y Vegetacional Actual}

La fisiografía del desierto de Atacama, correspondiente a la Región de Antofagasta, se compone de tres grandes unidades dispuestas en sentido longitudinal, diferenciables entre sí: la cordillera de los Andes, la depresión intermedia y la cordillera de la Costa. Inserto dentro de estas formaciones, el desierto de Atacama abarca la vertiente occidental del levantamiento andino entre los 15 y $30^{\circ} \mathrm{S}$, con elevaciones que van desde el nivel del mar a $3.500 \mathrm{~m}$ de altitud (Houston y Hartley 2003). Su existencia es el resultado del establecimiento de la corriente fría de Humboldt y el efecto "sombra de lluvia" producida por la cordillera de los Andes, que bloquea las masas de aire que traen humedad desde la cuenca amazónica y su posición latitudinal (Houston y Hartley 2003; Marquet et al. 1998). En este extenso desierto se reconoce a la Puna de Atacama como una planicie elevada de ca. $4.000 \mathrm{msm}$, cubriendo alrededor de $180.000 \mathrm{~km}^{2}$, surcada por cordones discretos respecto de la meseta frontal, pero de gran elevación en relación con el nivel del mar, emplazada de sur a norte en el Centro Sur andino. Representa a uno de los ecosistemas más frágiles e inhóspitos de los Andes, debido a los efectos combinados de bajas temperaturas y extrema aridez con adaptaciones humanas aisladas en torno a los escasos recursos naturales del desierto de altura.

A continuación se describe brevemente el transecto Tulán (Figura 1), localizado en el borde sureste del salar de Atacama (4.650 a $2.300 \mathrm{msm}$ ), con el fin de contextualizar el marco vegetacional y arqueológico de las muestras de polen fósil registradas en los depósitos del asentamiento Tulán-85. Para este efecto se caracterizan sus pisos o formaciones vegetales en los gradientes altitudinales actuales 
y se comparan con las muestras obtenidas de la columna ocupacional situada en el tramo más bajo del territorio.

Se trata de un piso vegetacional donde las vegas del salar se encuentran conectadas con la alta puna por quebradas intermedias, secas y fértiles. Estas últimas se constituyeron en hábitats estables con recursos de agua permanentes, lo que incidió temprano en la ubicación de numerosas ocupaciones que cubren una secuencia de más de 10.000 años (Núñez 1995). A través de la interacción del transecto Tulán estas comunidades articularon diversos pisos ecológicos con recursos complementarios dispuestos entre la zona altoandina y las playas del salar de Atacama, por medio de circuitos transhumánticos orientados a la obtención de recursos de subsistencia y de materias primas o bien mediante contactos más amplios de carácter macrorregional entre la costa y los ámbitos transandinos (Núñez 1995; Núñez et al. 2002; Núñez et al. 2006; Núñez et al. 2007).

Ciertamente, los recursos localizados en el piso altoandino, junto a los fondos de las quebradas fértiles, planicies de interfluvio y las vegas del salar constituyeron ambientes forrajeros tanto para los camélidos silvestres como para aquellos rebaños domésticos durante el Formativo Temprano. En tanto que los oasis piemontanos (ca. 2.300-2.700 msm), localizados en los desagües superficiales y subterráneos, se vincularon con espacios de arboledas de valor alimenticio como el algarrobo (Prosopis sp.) y chañar (Geoffrea decorticans Burk), incluyendo suelos aptos para las prácticas hortícolas suplementarias.

Se ha planteado que estas características ambientales no han sido estáticas en el tiempo; así, durante la transición Pleistoceno-Holoceno ha ocurrido un conjunto de cambios en el clima macrorregional, afectando fuertemente los montos de precipitaciones con tendencia hacia escenarios más secos, sujetos a variaciones intermedias, incidiendo en la composición de los ecosistemas vigentes, caracterizados por una baja diversidad de especies y alto grado de endemismo (Latorre et al. 2005, Moreno et al. 1994, Rundel et al. 1991). Actualmente la composición de la vegetación está influenciada por la diferencia altitudinal e involucra varios niveles de formaciones o pisos vegetacionales que difieren de mar a cordillera, caracterizados por un conjunto de especies dominantes con una fisionomía particular, asociados a un piso bioclimático específico. Para el caso particular del espacio de estudio se presentan al menos tres formaciones vegetales, de acuerdo con la clasificación de Luebert y Pliscoff (2006):

1. Matorral Desértico, representado por el matorral desértico tropical interior (2.400-2.500 msm) dominado por Atriplex atacamensis Phil. y Tessaria absinthioides (H.et A.) DC., que dentro de su composición florística tiene a Distichlis spicata (L.) Greene, Geoffroea decorticans (Gill. ex H.et A.) Buró., Prosopis alba Griseb, entre otros.

2. Matorral Bajo Desértico, subdividido en dos pisos vegetales:

A. Matorral Bajo Desértico Tropical Interior de Adesmia atacamensis Phil. y Cistanthe salsoloides (Barnéoud) Carolin ex Hershk (1.800-3.700 msm) con especies acompañantes como Dinemandra ericoides A.H.L. Juss, Ephedra breana Phil., Hoffmanseggia doellii Phil, entre otras.

B. Matorral Bajo Desértico Tropical Andino de Atriplex imbricada (Moq.) Dietr. y Acantholippia deserticota (Phil) Moldenke (3.500-3.800 msm), cuya composición florística incluye Chuquiraga kuschelii Acev., Opuntia atacamensis Phil., Stipa frigida Phil.

3. Matorral Bajo de Altitud, corresponde a un Matorral Bajo Tropical Andino que para este caso está dividido en tres pisos vegetales:

A. Matorral de Artemisia copa Phil. y Stipa frigida Phil. (3.800-4.000 msm) con un pequeño componente más variado, incluyendo Ephedra breana Phil, Fabiana denudata Miers, Hoffmanseggia eremophila (Phil.) Buró ex Ulib., entre otras especies.

B. Matorral de Fabiana bryoides Phil. y Parastrephia quadrangularis (Meyen) Cabr. (3.800$4.200 \mathrm{msm}$ ), cuya composición florística es menos rica que el piso anterior e incluye Adesmia melanthes Phil, Baccharis incarum Wedd, Senecio xerophilus Phil., entre otras especies.

C. Mulinum crassifolium Phil. y Urbania pappigera Phil. (4.200-4.900 msm), con importante presencia de gramíneas en mechón. En su composición florística están Festuca chrysophylla Phil., Stipa venusta Phil., Deyeuxia crispa Rúgulo y Villav., Adesmia caespitosa Phil, y otras.

A través de técnicas de harneado y flotación de materiales del sitio arqueológico Tu- 85 se identificaron macrorrestos vegetales. Se registró una columna de flotación (Test 1) con niveles de $20 \mathrm{~cm}$ durante las primeras excavaciones estratigráficas, donde se identificaron escasas semillas de Opuntia sp. y abundantes restos de Schoenoplectus americanus (Holden 1991). De este mismo perfil y 
a una profundidad de $40 \mathrm{~cm}$ (cuadrícula B7SE) se registraron sólo dos marlos de maíz con una datación obtenida del mismo nivel en una cuadrícula aledaña del orden de 970 a 760 cal. a.C. correspondientes hasta ahora a la única evidencia de marlos de maíz del sitio seguramente trasladados al sitio (Núñez 1999). El próximo análisis se logró de una segunda columna de flotación del mismo perfil del montículo, reiterándose el patrón en torno a la carencia de plantas cultivadas y a la alta diversidad de especies silvestres, provenientes en su mayoría del entorno del sitio. La mayor frecuencia corresponde a Atriplex sp. y a especies de las familias Cyperaceae y Poaceae (90\% de la muestra). Entre los registros de pisos más altos se encuentran Opuntia sp. y Solanum sp. Por otro lado, se observa una escasa presencia de semillas y residuos de vainas de Prosopis sp. y Geoffrea decorticans Burk (Bueno 2003). Nuevas excavaciones en este sitio permitieron ampliar la muestra para los análisis de macrorrestos, observándose el dominio de los recursos vegetales silvestres (91\%), luego una baja presencia de restos de artefactos elaborados en materia prima vegetal $(5 \%)$, además de recursos cultivados (3\%), entre los cuales domina Lagenaria sp. y, por último, mínimas especies no locales (1\%) (McRostie 2007, Núñez et al. 2009).

En suma, se espera a través del análisis polínico, obtener una secuencia paleovegetacional del asentamiento Tulán-85 con el fin de ajustar la secuencia paleoclimática a una escala más fina en torno a las ocupaciones formativas de la fase Tilocalar en las tierras bajas del salar de Atacama, asociadas a vegas forrajeras. La orientación hacia las prácticas de caza y crianza de camélidos debió exigir de espacios abiertos como las vegas de Tilocalar. En este sentido es de esperar que una menor recarga de acuíferos en el ámbito de las vegas del salar pudieron crear condiciones adversas para el forrajeo, con una menor disposición de plantas locales, generándose posibles eventos de estrés que pudieron afectar la crianza y caza de camélidos adaptados a la vegetación de las playas del salar y, por consiguiente, a las poblaciones humanas asociadas.

\section{Las Zonas Estratigráficas del Sitio Tulán-85}

El sitio Tulán-85 se ubica en el borde oriental del salar de Atacama (2.300 msm), asociado a extensos ambientes forrajeros, lagunetas y vertientes aisladas con amplias planicies favorables para las prácticas de recolección, caza y pastoreo. Los asentamientos sincrónicos Tulán-54 y 122 se encuentran localizados en el piso de quebradas intermedias, lo que les habría posibilitado el control directo de los recursos diversificados del total de los pisos vegetacionales a lo largo del transecto Tulán que une las tierras bajas del salar y la zona altoandina (Figura 1). El asentamiento Tulán-85 corresponde a una extensa ocupación orientada a labores domésticas, en cuyo sector central se ubica un depósito monticular conformado por una amplia diversidad de material cultural en una matriz estratificada de sedimentos finos, vegetales desintegrados, arena, cenizas y fogones compactos (Núñez 1992, 1995).

De acuerdo con la lectura del perfil obtenido de la excavación del montículo y de donde provienen las muestras de polen, se han distinguido tres zonas diferenciadas que en su conjunto explican el proceso de formación del sitio (Figura 3 y Anexo).

Zona estratigráfica temprana (niveles $210-80 \mathrm{~cm}$ ): La primera ocupación se instaló en una explanada geomorfológicamente estable delimitada por dos torrenteras laterales, sobre una matriz de arena deleznable y grava fina. Se observa el traslado de pendiente de toba descompuesta desde el afloramiento que limita al yacimiento por el este. Se observa escasa actividad dispersa asociada a dos bolsones socavados en la base estéril con ofrendas fundacionales (Figura 3, Estratos 14, 13 y 12). Luego se incrementó la ocupación con mayor uso de recursos vegetales entre gravilla dispersa por acción eólica, asociado al inicio de las inhumaciones de neonatos (NEO3), propias del patrón ritual de la fase Tilocalar. Se incrementan los lentes y depósitos de ceniza asociados a la preparación de alimentos, a juzgar por la presencia de un metate in situ (Estrato superpuesto 11). Hacia la parte superior, aumenta la potencia de los restos orgánicos que cubren los estratos anteriores, sin evidencias de intrusiones o perturbaciones depositacionales secundarias. Se superponen lentes de restos orgánicos oscuros y residuos finos de quemas y cenizas lenticulares, que culminan con la extensión de un potente fogón. $\mathrm{La}$ presencia de otra inhumación de neonato (NEO2) demuestra que se mantiene el ritual principal de la fase Tilocalar (Estrato 10).

Zona estratigráfica intermedia (niveles 100 a ca. $70 \mathrm{~cm}$ ): Sobre las capas anteriores se extendió un depósito de precipitación de ceniza volcánica, 
conformando una "bomba" o sello cementado de carácter conglomerado que manteó desde cerca de la cúspide del montículo a la pendiente del nivel ca. $100 \mathrm{~cm}$ (Wilke 2012). Este estrato 6 da inicio a una acumulación de capas con ceniza cultural, vegetales, restos orgánicos oscuros, lentes de fogones, restos de talla lítica, vestigios arqueofaunísticos abundantes y vegetales, incluyendo otra inhumación de neonato (NEO1). En estas dos zonas estratigráficas se observan los principales indicadores artefactuales del Formativo Temprano: puntas pedunculadas de obsidiana, industria de láminas de toba Tulán, manos, metates, cuentas, cerámica doméstica tipo Los Morros, artefactos óseos, fragmentos de láminas de oro, cobre fundido, conchas del Pacífico y del oriente, microperforadores, entre otras evidencias (Núñez et al. 2006). Respecto de la presencia de macrorrestos vegetales, ambas zonas estratigráficas ratifican una notable carencia de productos cultivados y una alta tasa de recolección de plantas silvestres.

\section{Zona estratigráfica tardía (niveles ca. $70-0 \mathrm{~cm}$ ):}

El montículo superior corresponde a un depósito tardío y homogéneo con abundante material vegetal (Estratos 3 y 2), bajo una leve acumulación estéril (Estrato 1), donde la superficie es aplanada por el efecto erosivo eólico. Estos estratos constituyen una espesa acumulación en discordancia depositacional con las capas previas, en cuanto no repiten los patrones de descarte ni los indicadores faunísticos de las zonas tempranas e intermedias. De hecho, no se registran fogones ni restos de ceniza asociada a labores domésticas y alimentarias. Por otro lado, no se manifiestan las típicas inhumaciones de neonatos de la fase Tilocalar. Se trataría de un depósito compuesto por pisos superpuestos de forrajeo para ganado. Estos cambios depositacionales con materiales vegetales triturados se asocian precisamente a un incremento de coprolitos de camélidos posiblemente asociado a la crianza en corrales.

En general, estas superposiciones de estratos a través de todo el perfil no demuestran en su base el efecto de evaporación del sustrato del salar, ni hiatos ocupacionales, en tanto que los sellos estratigráficos habrían inhibido el ingreso de polen trasladado, mientras que el efecto de posibles microclimas se habría limitado, toda vez que el hábitat comparte el paisaje abierto y homogéneo del borde de las vegas del salar de Atacama (Anexo).

La relación entre zonas estratigráficas, las columnas de polen y los sedimentos con la acumulación del descarte cultural señala que estos registros están directamente vinculados con actividades humanas, debidamente selladas por la superposición de los depósitos. En este sentido la locación de las tres dataciones $\mathrm{C}^{14}$ demostraría una correlación cronológica entre la estratigrafía cultural y la columna de muestreo por medio de una secuencia desde la base del montículo hacia la sección más superior relativamente cercana a la superficie (Figura 3 y Tabla 1 ).

El corte seccional del montículo estratificado (Test 1) presenta una altura máxima de $210 \mathrm{~cm}$ de profundidad, compuesto por sedimentos de origen local asociado a descartes culturales, sin hiatus ni perturbaciones, salvo la depositación de una lluvia de ceniza volcánica que con el efecto de "bomba" selló la ocupación inferior algo antes de los 1.250 a $900 \mathrm{cal}$. a.C. (Estrato 6), visible en el perfil de la cuadrícula E8. Un total de siete dataciones radiocarbónicas proviene del corte seccional in toto, cubriendo un rango desde una ocupación inicial por los 1.530 cal. a.C. alcanzando los eventos de abandono algo después de los 420 cal. a.C. (ver Anexo, M8).

Específicamente tres dataciones se lograron en el perfil B-B' (Cuadrículas F8 y E8), de donde proviene la columna de polen (Figura 3). La muestra $\mathrm{N}^{\mathrm{o}} 17$ o más temprana es sincrónica con la datación del orden de los 1.410 cal. a.C. (Estrato 12: M 3). Las muestras $\mathrm{N}^{\circ} 5$ y 6 son contemporáneas con la datación de 1.250 cal. a.C. (Estrato 5: M 2). Finalmente, las muestras $N^{o s} 1,2$ y 3 son las más tardías, sincronizadas con la datación de 1.010 cal. a.C. (Estrato 3: M 1). Es decir, todo el depósito del perfil muestreado cubre un rango cronológico desde los 1.410-1.010 cal. a.C., cubriendo aproximadamente algo más de 400 años de ocupación. Si se considera ahora el total de las dataciones del montículo, el rango cronológico de la acumulación estratigráfica sería de 1.110 años. Con estas consideraciones se puede proponer que la estratificación cultural desde el comienzo de ocupación a los episodios cercanos al abandono del yacimiento tuvo lugar durante un rango máximo del orden de los 1.110 años de ocupación continua, tiempo en que pudieron ocurrir fluctuaciones climáticas significativas (Tabla 1). 


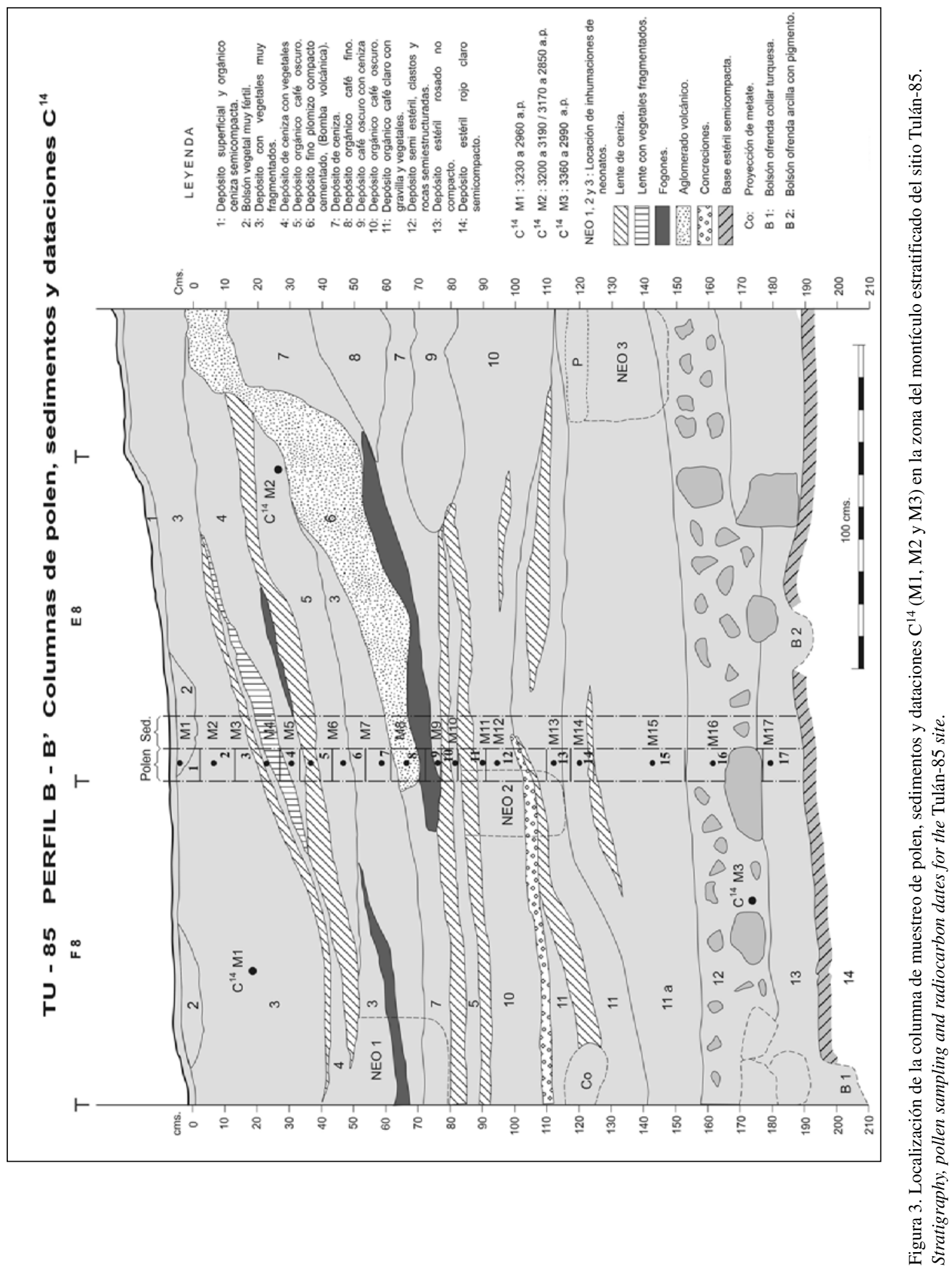


Tabla 1. Fechados radiocarbónicos del sitio Tulán 85/Montículo. Radiocarbon dates from the Tulán 85/Montículo site.

\begin{tabular}{|c|c|c|c|c|c|}
\hline $\begin{array}{l}\text { Correlación estratigráfica } \\
\text { en perfil polínico }\end{array}$ & $\begin{array}{c}\text { Convencional } \\
\text { no calibrada a.p. }\end{array}$ & $\begin{array}{c}\text { Calibrada a.C. } \\
2 \text { sigma }\end{array}$ & Cuadrícula & Material & $\mathrm{N}^{\mathrm{o}}$ Laboratorio \\
\hline $\begin{array}{c}\text { Perfil sector sur } \\
\text { Proyección: Estrato } 3 \\
\text { (Perfil polínico M-2) }\end{array}$ & $\begin{array}{l}2.500 \pm 40 \\
\text { AMS }\end{array}$ & $\begin{array}{l}790 \text { a } 490 \text { cal. a.C. } \\
460 \text { a } 420 \text { cal. a.C. }\end{array}$ & $\begin{array}{c}\text { F8 } \\
\text { Ocupación media } \\
\text { a superior }\end{array}$ & Carbón & Beta 240193 \\
\hline Perfil sector sur & $2.660 \pm 80$ & 970 a 760 cal. a.C. & $\begin{array}{c}\text { D7 } \\
\text { Ocupación media }\end{array}$ & Carbón & Beta 32388 \\
\hline $\begin{array}{l}\text { Test-1 }\left(\mathrm{C}^{14} \mathrm{M} 2\right), \text { Estrato } 5 \\
\quad \text { (Perfil polínico } \mathrm{M}-7)\end{array}$ & $2.860 \pm 60$ & $\begin{array}{c}1.250 \text { a } 1.240 \text { cal. a.C. } \\
1.220 \text { a } 900 \text { cal. a.C. }\end{array}$ & $\begin{array}{c}\text { E8 } \\
\text { Ocupación superior }\end{array}$ & Carbón & Beta 254439 \\
\hline $\begin{array}{c}\text { Perfil sector sur } \\
\text { Proyección: Estrato 2-a } \\
\text { (Perfil polínico M-12) }\end{array}$ & $\begin{array}{l}2.900 \pm 40 \\
\quad \mathrm{AMS}\end{array}$ & $\begin{array}{c}1.250 \text { a } 1.240 \text { cal. a.C. } \\
1.220 \text { a } 980 \text { cal. a.C. }\end{array}$ & $\begin{array}{c}\text { F8 } \\
\text { Sobre inicio } \\
\text { ocupación }\end{array}$ & Carbón & Beta 240194 \\
\hline $\begin{array}{c}\text { Test-1 }\left(\mathrm{C}^{14} \mathrm{M} 1\right) \text {, Estratos } \\
1,2 \text { y } 3\end{array}$ & $\begin{array}{l}2.940 \pm 40 \\
\quad \text { AMS }\end{array}$ & 1.280 a 1.010 cal. a.C. & $\begin{array}{c}\text { F8 } \\
\text { Ocupación superior }\end{array}$ & Carbón & Beta 256436 \\
\hline Test-1 ( $\left.\mathrm{C}^{14} \mathrm{M} 3\right)$, Estrato 12 & $3.000 \pm 60$ & 1.410 a 1.040 cal. a.C. & $\begin{array}{c}\text { F8 } \\
\text { Inicio ocupación }\end{array}$ & Carbón & Beta 240192 \\
\hline $\begin{array}{c}\text { Perfil sector sur } \\
\text { (Perfil polínico } \mathrm{M}-15)\end{array}$ & $3.140 \pm 70$ & 1.530 a 1.260 cal. a.C. & $\begin{array}{c}\mathrm{C} 7 \\
\text { Inicio ocupación }\end{array}$ & Carbón & Beta 25508 \\
\hline $\begin{array}{l}\text { Test extra perfil } \\
\text { M } 54\end{array}$ & $\begin{array}{c}940 \pm 40 \\
\text { AMS }\end{array}$ & $\begin{array}{l}1.020 \text { a } 1.200 \text { cal. d.C. } \\
930 \text { a } 750 \text { cal. d.C. }\end{array}$ & $\begin{array}{c}\mathrm{C} 1 \\
\text { Ocupación tardía }\end{array}$ & Carbón & Beta 240195 \\
\hline
\end{tabular}

\section{Materiales y Métodos}

\section{Muestreo}

Dieciséis muestras del sitio Tulán 85/Montículo fueron tratadas para el análisis polínico de un total de 17, en cuanto el registro volcánico (M 8) no fue examinado (ver Anexo). En esta dirección se concentró la atención en el piso vegetacional inferior del transecto descrito y su eventual representación en el corte seccional excavado en el núcleo del montículo, situado a unos $800 \mathrm{~m}$ de las vegas fuera de las playas de inundación del salar. Este registro proviene de una secuencia cronoestratigráfica continua, donde se preparó una columna para la extracción de 17 bloques de ca. $10 \mathrm{~cm}^{3}$, cubriendo la altura total del montículo (Figura 3). Estas muestras se describen a continuación.

M1 (0-11,5 cm): Estrato café claro fértil (alta densidad de evidencias culturales y ecofácticas), disgregado, con restos vegetales finos y macrorrestos, lascas, residuos orgánicos y fragmentos de coprolitos de camélidos en una matriz de sedimento eólico y orgánico triturado.

M2 (11,5-20 cm): Estrato café/gris, fértil, disgregado, con restos vegetales fibrosos y óseos muy fragmentados, asociados a macrorrestos y partículas de carbón, en una matriz con pequeñas concreciones, arena eólica y sedimento orgánico fino.

M3 (20-35,5 cm): Estrato gris fértil, disgregado, con vegetales muy fragmentados y macrorrestos, partículas de carbón y óseos en matriz de arena eólica, sedimento orgánico fino y pequeñas concreciones orgánicas.

M4 (35,5-40 cm): Estrato café/gris fértil, semidisgregado, con vegetales muy fragmentados, asociados a macrorrestos y partículas de carbón en una matriz de arena eólica con sedimento orgánico de origen vegetal y descomposición de roca.

M5 (40-50 cm): Estrato gris fértil, disgregado, asociado a macrorrestos con partículas de carbón, derivado de combustión aledaña, en una matriz de arena eólica y sedimento orgánico fino. 
M6 (50-60 cm): Estrato café fértil, disgregado, con vegetales muy fragmentados, asociados a partículas de carbón y macrorrestos vegetales, en matriz de arena eólica con sedimentos orgánicos finos y restos débiles de combustión.

M7 (60-68 cm): Estrato gris fértil, disgregado, con restos finos de combustión, partículas de carbón, escasos restos vegetales, en una matriz de roca descompuesta y sedimento fino con arena eólica y partículas carbonosas.

M8 (68-78 cm): Estrato-sello plomizo estéril, concrecionado y muy compacto con intrusiones de materiales combustionados, en una matriz aglomerada volcánica (muestra no analizada).

M9 (78-81 cm): Estrato café semiestéril, con escasas partículas de carbón y huesos muy fragmentados en matriz de arena eólica y gravilla angular regular a fina, derivada de roca descompuesta.

M10 (81-87 cm): Estrato café semiestéril con concreciones aisladas de regular factura, asociadas a pequeñas rocas en proceso de descomposición. Presencia de partículas de carbón y escasos huesos muy fragmentados, en matriz semiaglomerada con arena y abundante gravilla regular.

M11 (87-94 cm): Estrato café semiestéril, asociado a pequeñas rocas de regular factura, escasas partículas de carbón y restos óseos fragmentados en una matriz aglomerada de arena eólica y gravilla angular regular a mínima.

M12 (94-118 cm): Estrato café cremoso semiestéril con escasos restos vegetales y óseos fragmentados, en una matriz de arena con gravilla y sedimento derivado de roca descompuesta.

M13 (118-124 cm): Estrato café semifértil con escasas partículas de carbón, huesos y roca descompuesta fina.

M14 (124-160 cm): Estrato café semiestéril con escasas partículas de carbón y vegetales mínimos en una matriz aglomerada de gravilla de mayor factura. M15 (160-185 cm): Estrato café semiestéril con escasas partículas de carbón, restos óseos y vegetales muy fragmentados, en matriz aglomerada de gravilla gruesa de mayor factura con sedimento fino, arena $\mathrm{y}$ restos de roca descompuesta.

M16 (185-200 cm): Estrato café claro estéril con fragmento de roca de regular factura, en matriz de arena gruesa, roca descompuesta, gravilla regular fina y escasas partículas de carbón.

M17 (200-205 cm): Depósito estéril de base con sedimento rosado fino, asociado a gravilla regular a fina, roca descompuesta, en una matriz compacta de arena gruesa y fina derivada de la descomposición de la roca madre (Núñez y Lorca 2009).

Además, se colectaron 25 muestras de suelo superficial, para análisis de lluvia de polen, con el objetivo de estudiar la dispersión polínica actual. Estas últimas fueron colectadas en un gradiente altitudinal, desde el salar El Laco a 4.650 msm cerca de la frontera chileno-argentina, hasta los $2.250 \mathrm{msm}$ cercanos al salar de Atacama (Figura 4). La importancia de este análisis radica en lograr una comprensión local más acabada de la distribución polínica actual para una mejor interpretación de los resultados de polen fósil, estrategia utilizada en otros trabajos de esta naturaleza (p.ej. Heusser 1990; Kuentz et al 2007; Maldonado et al. 2005). Estos controles propios del estudio polínico se orientan a validar su carácter de indicador en la problemática del cambio climático, pero a su vez son relevantes, porque permiten valorar y reconstituir el paisaje vegetacional del entorno de los asentamientos subactuales y con ello entender mejor las relaciones con las poblaciones locales.

\section{Procesamiento}

La extracción del polen de las muestras de sedimento se realizó mediante técnicas de rutina (Faegri e Iversen 1989). Se procesó 1 cc de sedimento de cada muestra. Previo al tratamiento físico-químico se agregaron a cada muestra dos pastillas con esporas de Lycopodium sp. para calcular la concentración polínica (granos de polen/ $\mathrm{cm}^{3}$ de sedimento; Stockmarr 1971). El tratamiento consistió en defloculación de arcillas y eliminación de ácidos húmicos con $\mathrm{KOH}$ al 10\%; remoción de los carbonatos con $\mathrm{HCl}$ al 10\%; remoción de silicatos con HF y acetólisis. Del extracto obtenido se tomó una alícuota para ser observada al microscopio (con un aumento de 1000 y 400 X), haciendo un recuento no inferior a 300 granos de polen por muestra, excluyendo de esta suma básica los taxones palustres y acuáticos, los que fueron calculados basados en la suma total.

Los niveles M16 y M17, pertenecientes a las muestras arqueológicas, resultaron polínicamente estériles. El nivel M8 no fue procesado por tratarse de un sello compacto y estéril, sin sedimentos disgregados. En cinco muestras de lluvia de polen actual, para las altitudes: 2.650, 2.550, 2.450, $2.350 \mathrm{y}$ $2.250 \mathrm{msm}$ el contenido de polen resultó insuficiente para realizar un recuento estadísticamente confiable. Los resultados de los recuentos polínicos tanto fósiles 


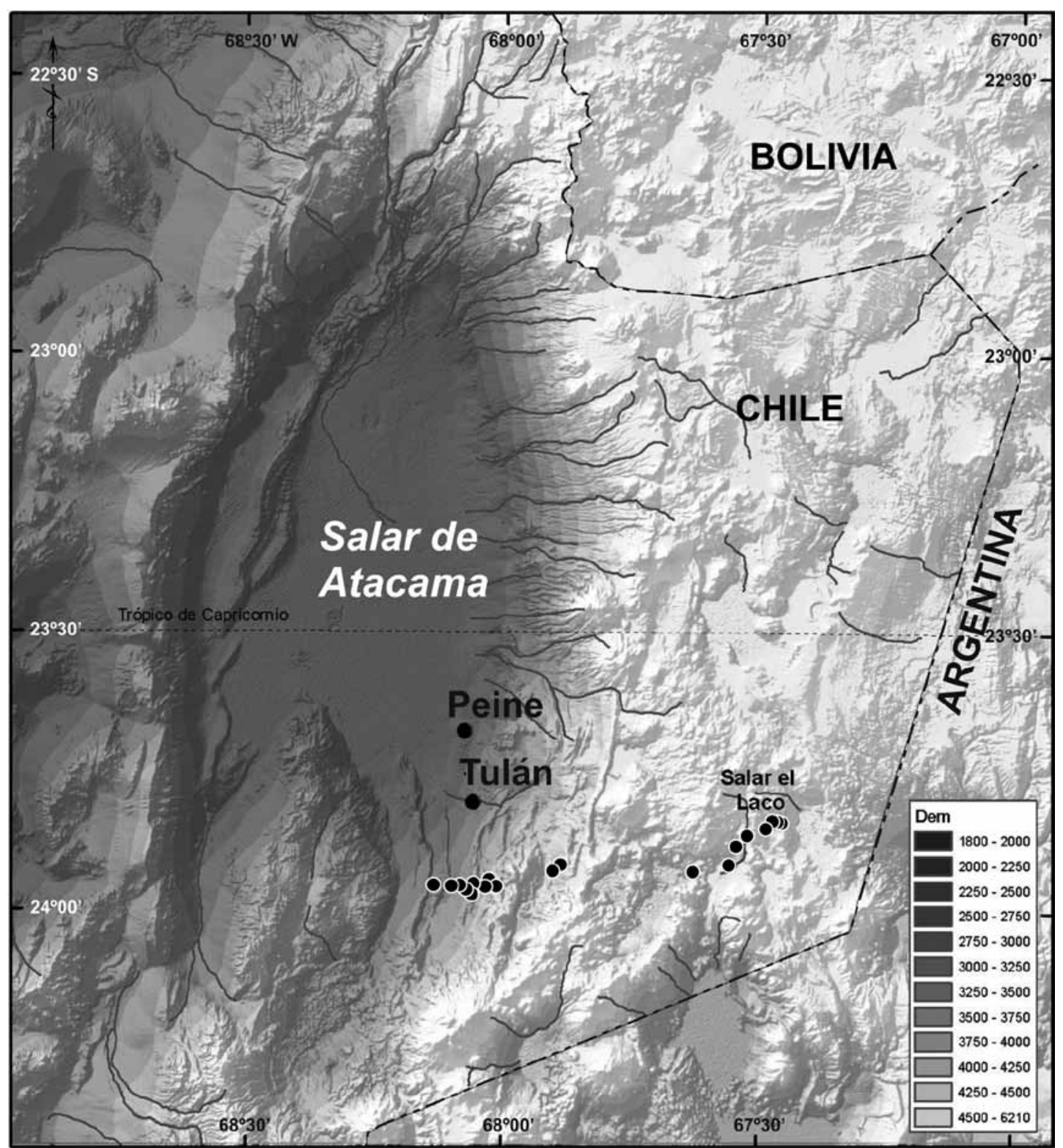

Figura 4. Mapa del área de estudio basado en un modelo de elevación digital (DEM). Los círculos negros con borde blanco indican sectores de muestreo de lluvia de polen actual. Los círculos negros de mayor tamaño indican la ubicación aproximada del sitio arqueológico TU-85 y localidades cercanas.

Map of the study area based on a Digital Elevation Model (DEM). Black circles with white border indicate locations of modern pollen samples. Larger black circles indicate TU-85 and other close sites.

como actuales son presentados en diagramas de porcentajes polínicos, son calculados sobre la suma básica de recuentos (excluyendo acuáticas y palustres), y como diagramas de concentraciones (granos de polen $/ \mathrm{cm}^{3}$ de sedimento). En los diagramas de porcentajes polínicos de ambos grupos de datos se realizó un análisis de conglomerados, utilizando el programa CONISS (Constrained Incremental Sums of Squares; Grimm 1987), esto ayuda a delimitar las zonas polínicas, lo que permite agrupar muestras con mayor homogeneidad en un grupo y la mayor diferencia entre grupos, pero respetando el orden estratigráfico de éstas. La comparación entre ambos grupos excluyó los taxones palustres. 


\section{Resultados}

\section{Registro polínico del asentamiento Tulán-85}

La secuencia palinológica de Tulán-85 (Figuras 5 y 6) comprende 16 niveles, sólo en 14 de ellos fue posible encontrar polen en cantidades suficientes para realizar el análisis propuesto. A continuación se describen los principales cambios registrados en los porcentajes polínicos, los cuales son corroborados por los cálculos de concentración polínica. Los diagramas han sido divididos en cuatro zonas polínicas, con ayuda del programa CONISS (Grimm 1987), desde la más antigua (zona 1) a la más reciente (zona 4).

Zona 1 (muestras TU85M-15 hasta TU85 M-14): Dominada por polen de Ephedra sp. y de especies de las familias Chenopodiaceae y, en menor grado, Poaceae tipo Stipa. La familia palustre Cyperaceae presenta porcentajes cercanos al $35 \%$.

Zona 2 (muestras TU85M-13 hasta TU85 M-10): Caracterizada por el dominio polínico de Ephedra sp., acompañado de Poaceae tipo Stipa y valores en descenso de Chenopodiaceae. La familia Cyperaceae mantiene altos valores la mayor parte de la zona.

Zona 3 (muestras TU85M-9 hasta TU85 M-4): La parte inferior (las tres muestras basales) está dominada por polen de Asteraceae tipo Senecio y Chenopodiaceae, acompañados por proporciones menores de Ephedra sp., así como también de las familias Poaceae y Fabaceae tipo Adesmia. La parte superior (las dos muestras más cercanas al tope de la secuencia) de esta zona está dominada por las familias Portulacaceae y luego Fabaceae tipo Adesmia, acompañados de Chenopodiaceae, de manera decreciente. La familia Cyperaceae muestra altas proporciones a lo largo de toda la zona, disminuyendo levemente hacia el final.

Zona 4 (muestras TU85M-3 hasta TU85 M-1): Muestra inicialmente el dominio de Fabaceae tipo Adesmia, acompañada de Chenopodiaceae, las que hacia el final de la zona invierten su dominancia. Durante toda esta zona la familia Cyperaceae mantiene valores muy bajos.

Diagrama de concentraciones: El diagrama de concentraciones polínicas del registro Tulán-85 (Figura 6) muestra tendencias similares al diagrama de porcentajes, exhibiendo importante presencia de polen de Poaceae tipo Stipa en la zona 1 y 2, en esta última acompañado por polen del género Ephedra, principalmente en la zona 2. La zona 3 muestra bastante variabilidad en las concentraciones de la mayoría de los taxones, con presencia relativamente importante de las familias Brassicaceae y Poaceae tipo Festuca. La última zona se caracteriza por los máximos valores de Chenopodiaceae, destacando también la presencia de Cactaceae, Malphigiaceae, Solanaceae, Fabaceae, entre otras, y la casi total ausencia de Cyperaceae.

\section{Lluvia de polen actual en el transecto salar El Laco-salar de Atacama}

Los diagramas de porcentajes y concentraciones polínicas del transecto de lluvia de polen actual realizado entre el salar El Laco y el salar de Atacama se dividieron en tres zonas, las que han sido asignadas a algunos de los pisos de vegetación descritos y definidos en Luebert y Pliscoff $(2004,2006)$. A continuación se describen éstas desde la menor altura hasta la de mayor altura (Figuras 7 y 8 ).

Zona 1 (2.750-3.450 $\mathbf{~ m s m ) : ~ H a ~ s i d o ~ a s i g n a d a ~ a l ~}$ piso del Matorral Desértico, y está caracterizada por el casi exclusivo dominio de Chenopodiaceae, acompañado de Brassicaceae, con porcentajes considerablemente menores.

Zona 2 (3.550-4.040 msm): Corresponde al piso de Matorral Bajo Desértico y está dominada por polen del género Ephedra y la familia Fabaceae tipo Adesmia, en la parte inferior, acompañada de las familias Poaceae tipo Stipa y Chenopodiaceae en la parte superior de la zona.

Zona 3 (4.150-4.650 msm): Pertenece al piso de Matorral Bajo de Altura, está dominada por polen de Poaceae, acompañada de Fabaceae tipo Adesmia en el comienzo de la zona, Apiaceae y Chenopodiaceae.

El diagrama de concentraciones polínicas del transecto de lluvia de polen actual realizado entre el salar El Laco y el salar de Atacama (Figura 8) permite ver con mayor claridad del dominio polínico de los diferentes taxones descritos en el diagrama de porcentajes, destacando algunos taxones con bajos valores de porcentaje. Así, se observa cómo en el piso altitudinal inferior domina la familia Chenopodiaceae, acompañada de las familias Brassicaceae y Cactaceae. El piso intermedio muestra la presencia del género Ephedra y las familias Fabaceae tipo Adesmia, Asteraceae y Poaceae tipo Stipa. Mientras que el piso superior registra los mayores valores de Poaceae tipo Festuca, acompañado de Poaceae tipo Stipa y diversos tipos polínicos de Asteraceae. 


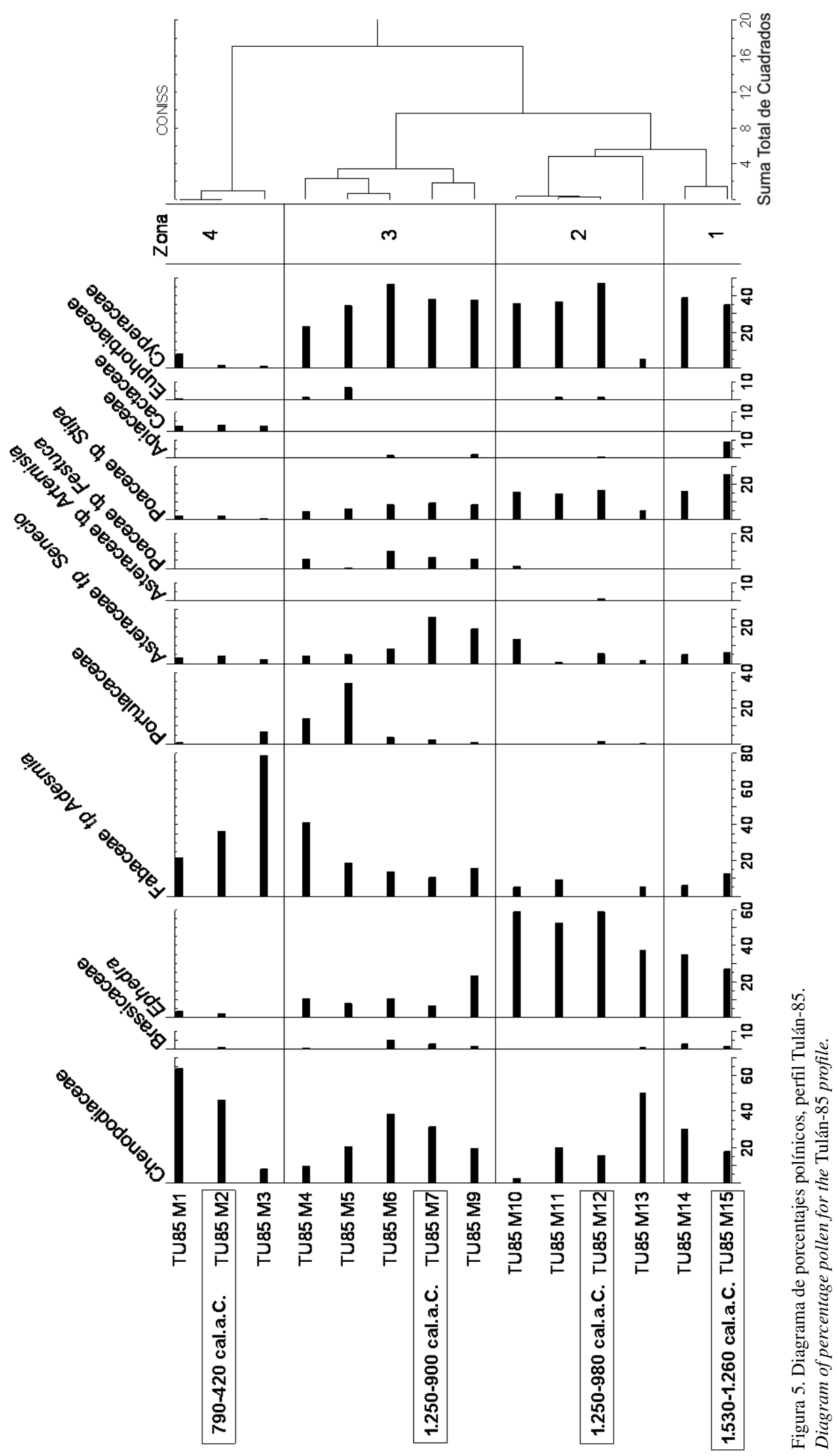




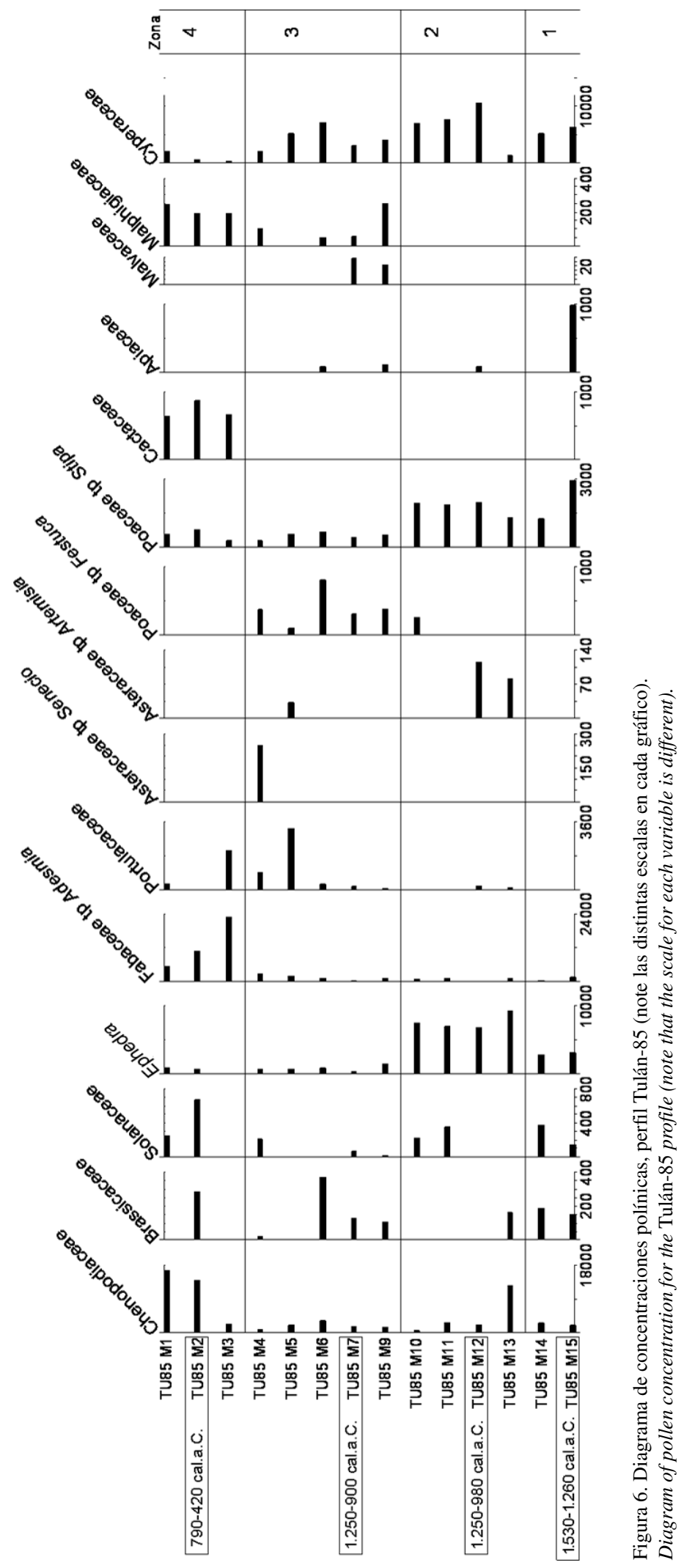




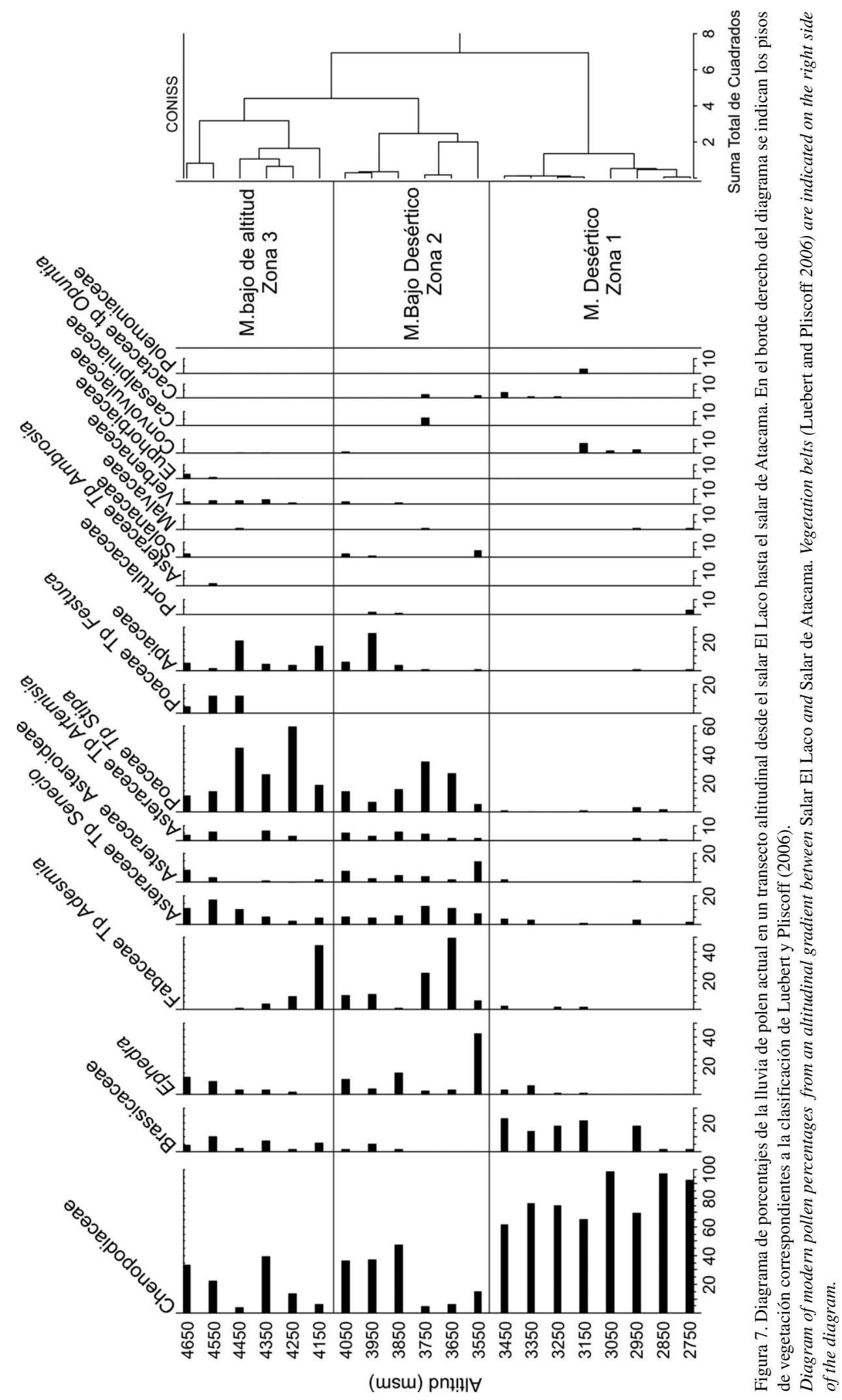









\section{Integración de los resultados polínicos}

El análisis de conglomerados realizado, juntando los porcentajes polínicos de las muestras del registro logrado en Tulán-85 y la lluvia de polen actual (Figura 9), muestra las mayores cercanías entre la muestra fósil TU85-M6 y espectros polínicos correspondientes a altitudes sobre $4.000 \mathrm{msm}$. De igual manera, pero algo menos cercanas entre sí, son las relaciones entre las muestras fósiles TU85-M9 y TU85-M7, espectros polínicos actuales correspondientes a altitudes en torno a $4.550 \mathrm{msm}$. Por otro lado la muestra actual de $3.550 \mathrm{msm}$ se asocia con las fósiles TU85-M10 a la TU85-M12, y en menor grado con las muestras fósiles TU85-M13 a TU85-M15. Las muestras TU85-M3 y TU85-M4, quedan asociadas aunque no de manera cercana con espectros actuales correspondientes a altitudes entre $3.650-4.150 \mathrm{msm}$. Finalmente, una asociación no cercana se da también entre las muestras TU85-M1, TU85-M2 y TU85-M5, con espectros polínicos actuales de altitudes entre 4.650-3.850 msm.

\section{Discusión y Conclusiones}

Los análisis de lluvia de polen actual permiten diferenciar claramente, de acuerdo con los diagramas de porcentajes, tres pisos de vegetación, de menor a mayor altitud: un piso dominado polínicamente por las familias Chenopodiaceae y acompañado de Brassicaceae, entre 3.450-2.750 msm. Un piso intermedio con dominio del género Ephedra y de las familias Fabaceae, Poaceae y Chenopodiaceae en la parte superior, entre 4.050-3.550 msm. Y un piso superior dominado por la familia Poaceae acompañado por Chenopodiaceae y Fabaceae en menores proporciones, entre $4.650-4.150 \mathrm{msm}$. Por otro lado, el diagrama de concentraciones polínicas complementa esta información mostrando cantidades absolutas de las familias Chenopodiaceae, Cactaceae y Brassicaceae, casi exclusivamente en el piso altitudinal inferior, y de igual manera definiendo más claramente los taxones dominantes en los pisos superiores. Un caso singular en este sentido es Chenopodiaceae, que se encuentra

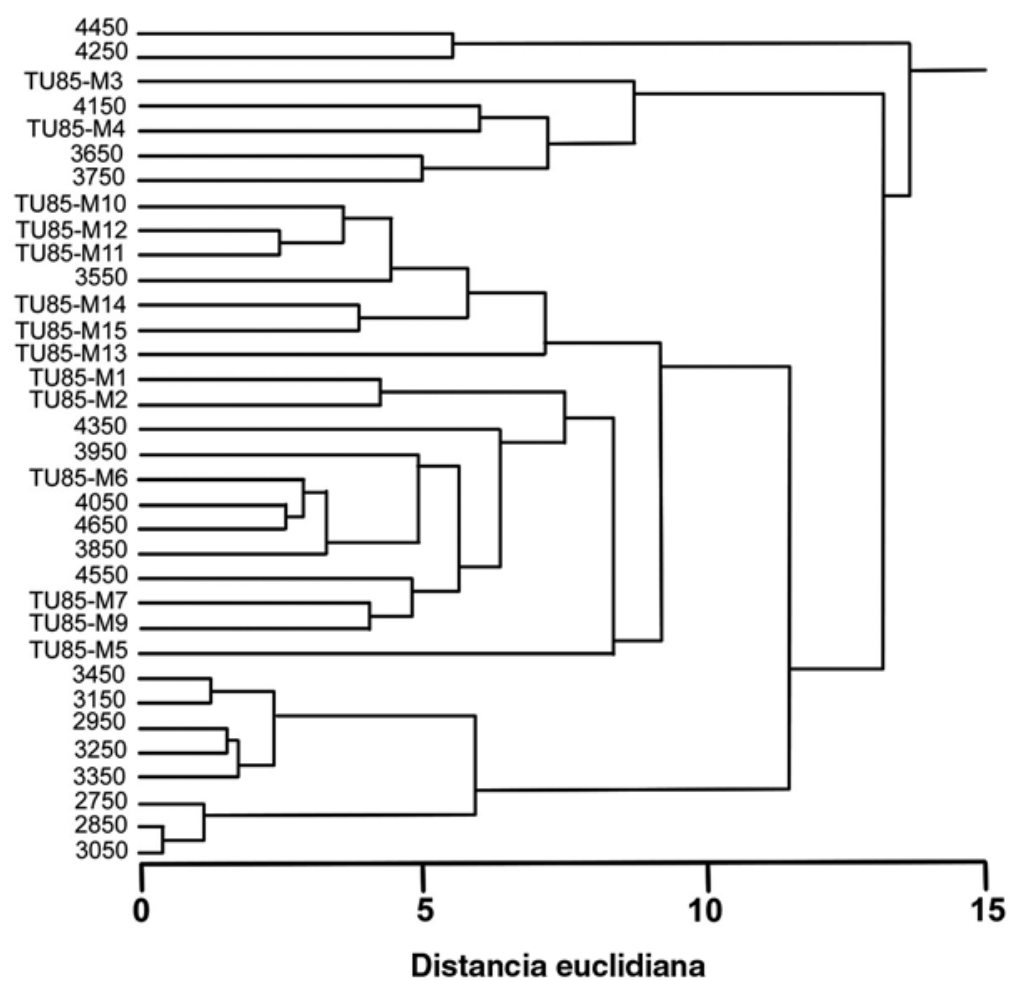

Figura 9. Análisis de conglomerados entre las muestras del registro Tulán-85 y lluvia de polen actual del transecto salar El Laco-el salar de Atacama.

Cluster analysis between pollen samples from Tulán-85 and those from the altitudinal gradient between Salar El Laco and Salar de Atacama. 
registrada en los pisos medio y superior con valores intermedios en el diagrama de porcentajes, sin embargo, el diagrama de concentraciones muestra que las cantidades absolutas de este taxón son considerablemente inferiores a las del piso inferior, sugiriendo una dispersión a larga distancia de este taxón, más que una presencia local en los pisos altitudinales superiores.

El diagrama de porcentajes polínicos de la columna Tulán- 85 sugiere, a partir de los altos valores de Cyperaceae, que probablemente la mayor parte del periodo transcurrido entre las zonas 1 y 3 estuvo asociado a un cuerpo de agua cercano. Por otro lado, considerando la lluvia de polen actual, los diagramas polínicos de porcentaje y concentración de la columna sugiere para las zonas 1 y 2 un ensamble de vegetación similar a la del actual piso altitudinal intermedio, con altos valores del género Ephedra y la familia Poaceae tipo Stipa. Esto es corroborado por el dendrograma de similaridad obtenido a partir del análisis de conglomerado realizado en ambos grupos de muestras. Por su parte, las zonas polínicas 3 y 4 sugieren ensambles de vegetación algo más similar a la presente actualmente en los pisos bajos analizados, con la presencia de las familias Chenopodiaceae, Cactaceae, Portulacaceae, entre otras.

Pese a que el análisis de conglomerado relaciona algunas muestras de las zonas 3 y 4 con espectros polínicos de pisos altitudinales superiores, este resultado debe considerarse con cierta precaución, ya que las mayores proporciones de Chenopodiaceae en los espectros fósiles pueden deberse a situaciones locales asociadas a formaciones vegetales azonales. Así, una interpretación posible es una tendencia a la disminución de la humedad local durante la zona 4, con el reemplazo de las Cyperaceae por Chenopodiaceae azonales, lo cual implica una disminución de la humedad local, debido a que las primeras tienen mayores requerimientos hídricos que las últimas. Adicionalmente esta zona presenta taxones asociados a los pisos desérticos, como son las familias Portulacaceae, Brassicaceae y como puede ser la familia Fabaceae, tipo Adesmia, del mismo modo que las Chenopodiaceae zonales.

Aunque para llegar a una conclusión más acertada se requiere de un mayor conocimiento sobre posibles vectores de contaminación polínica durante estos eventos, se asume que el registro fósil corresponde a polen proveniente de la vegetación natural del sector y posiblemente también a aquel depositado por la actividad humana en la zona, que de alguna manera también dependería de la disponibilidad local de recursos vegetales. Se sugiere como interpretación preliminar el desarrollo de condiciones relativamente húmedas, tanto zonales como azonales en torno a las zonas polínicas 1 y 2 , con mayores niveles de humedad en la zona polínica 2, y una tendencia a la disminución de la humedad en la zona polínica 3, sin embargo, aún bajo condiciones de humedad local. Mientras que la zona polínica 4 presentaría condiciones de mayor aridez, con ausencia de Cyperaceae y presencia de taxones de los pisos desérticos. Pese al carácter local del registro polínico, debido en parte por la naturaleza del depósito (origen mixto con componentes naturales y antrópicos), este registro es concordante con otras evidencias de carácter más regional documentadas para este período (Grosjean et al 2001; Latorre et al 2003; Latorre et al 2006).

De acuerdo con lo anterior, las vegas de Tilocalar, donde se concentró la ocupación del asentamiento Tulán-85, sustentaron un hábitat con condiciones paleoambientales favorables. El hecho de que las zonas polínicas 1,2 y 3 se hayan asociado a un cuerpo de agua cercano significaría que durante el tercer milenio a.p. efectivamente el nivel freático se ubicaba en una cota más alta de la actual, constituyendo espejos de agua de notable valor para la subsistencia. Episodios similares aún dan cuenta de la exposición de lagunetas relictuales en otros sectores del borde oriental del salar de Atacama.

Por otra parte, la presencia de taxones fósiles vinculadas con ambientes húmedos durante el periodo transcurrido entre las zonas 1 y 2 confirman el desarrollo de tempranas condiciones húmedas que en su conjunto incrementaron el forrajeo. En efecto, al observar el perfil del muestreo (Figura 5) se advierte que los registros de la zona 1 (M15 y $14 / 124$ a $185 \mathrm{~cm}$ de profundidad) y la zona 2 (M13, 12,11 y $10 / 81$ a $124 \mathrm{~cm}$ de profundidad) se datarían por los 1.410 cal. a.C. y los 1.250 cal. a.C. Mientras que la zona 3 (M9, 8, 7, 6, 5 y 4/78 a 35,5 cm de profundidad) demostraría una disminución de los recursos vegetales, aunque con cierta humedad local. Finalmente, en la zona 4 (M3, 2 y 1/35,5$0 \mathrm{~cm}$ de profundidad) a partir de los $1.010 \mathrm{cal}$. a.C. las condiciones de aridez fueron dominantes, constatadas a partir de la presencia de taxones de zonas desérticas.

Debe considerarse, además, el efecto adverso en términos de preservación del hábitat ocurrido inmediatamente antes de los eventos de aridez de la 
zona 4. En efecto, se ha detectado en el estrato 6 la presencia de una intensa lluvia de ceniza volcánica correspondiente a un evento regional detectado en este caso a través de "bombas" volcánicas que constituyeron un conglomerado compacto visible en el perfil estratigráfico (Figura 3). Este evento podría fecharse tentativamente como levemente anterior a los 1.250-900 cal. a.C. Sin embargo, la sobreposición inmediatamente sobre el material volcánico de restos orgánicos y culturales indicaría que este evento excepcional no fue suficiente como para motivar el abandono del hábitat, pero sí puede considerarse como un factor que junto con la aridez creciente de las capas superiores estimuló cierto deterioro del paisaje o quizás el abandono del asentamiento.

Se ha indicado que los recursos vegetales asociados al asentamiento Tulán- 85 se representan por plantas de uso alimenticio, principalmente silvestres y forrajeras, creándose un espacio eficiente para las prácticas de crianza de camélidos. El registro polínico de las zonas 1 a 3 ratifica la presencia de plantas propicias para la concentración de camélidos, tanto domésticos como silvestres (Cartajena et al. 2007; López et al. 2012; Núñez et al. 2009), lo que se relacionaría con el desarrollo de asentamientos densos como Tulán-85. Este sector fue articulado hasta hace pocos años sólo por pastores de la comunidad de Peine y Tilomonte, correspondientes a los oasis más cercanos, a través de ocupaciones temporales a lo largo de escalas discretas, de los cuales quedan como vestigios grandes corrales y algunas estancias no vinculadas con actividades agrícolas (M. Núñez 2000).

Los resultados del análisis polínico permitieron identificar la recuperación de humedad durante el Holoceno Tardío, coincidentes con la emergencia de labores pastoralistas desde ca. $1.500 \mathrm{cal}$. a.C. en el piso inferior del transecto alta puna al salar de Atacama, concluyendo con la identificación de un gradiente de mayor a menor humedad en la secuencia sustentada en las seis fechas del corte seccional, esto es entre las dataciones extremas 1.530-1.260 cal. a.C. a 460-420 cal. a.C. Al considerar estas dataciones del inicio y final relativo de la ocupación del montículo, se sugiere que en este rango cronológico tuvo lugar la transición desde un régimen de humedad a otro de mayor aridez mediante un patrón continuo de ocupación en torno a las vegas del salar. Durante esta secuencia habrían ocurrido tardíamente dramáticas descargas volcánicas y posteriores episodios de sequías que pudieron incidir en las actividades locales y/o regionales, provocando quizás una disminución de los recursos vegetales, cuyo impacto en las ocupaciones humanas tardías pudo implicar el traslado a otros recursos alternativos (v.gr. oasis piemontanos) o un severo reajuste de los patrones de asentamientos locales orientados esta vez a la explotación simultánea de las vegas forrajeras del salar y de los oasis arbolados y agrarios aledaños.

Agradecimientos: Los dos primeros autores agradecen el apoyo de los Proyectos Fondecyt 1080458 y Fondecyt 1130279. El presente estudio se desarrolló en el marco del Proyecto Fondecyt 1070040 y los coautores agradecen a su vez a todos los colaboradores tanto de terreno como de laboratorio, con especial reconocimiento al Prof. Dr. H. Wilke, geólogo de la Universidad Católica del Norte y a la comunidad atacameña de Peine, en cuyo ámbito se desarrolla la presente investigación. A los evaluadores externos por sus importantes recomendaciones.

\section{Referencias Citadas}

Abbott, M.B., B.B. Wolfe, A.P. Wolfe, G.O. Seltzer, R. Aravena, G.B. Mark, P.J. Polissa, D.T. Rodbell, H.D. Rowe y M. Vuille 2003. Holocene paleohidrology and glacial history of the Central Andes using multiproxy lake sediment studies. Palaeogeography, Palaeoclimatology, Palaeoecology 194:123-138.

Betancourt, J.L., C. Latorre, J.A. Rech, J. Quade y K.A. Rylander 2000. A 22,000-year record of monsoonal precipitation from Northern Chile's Atacama Desert. Science 289(5484):1542-1546.

Bobst, A.L., T.K. Lowenstein, T.E. Jordan, L.V. Godfrey, T.L. Ku, y S. Luo 2001. A 106 ka paleoclimate record from drill core of the Salar de Atacama, Northern Chile. Palaeogeography, Palaeoclimatology, Palaeoecology 173:21-42.
Bueno, L. 2003. Flotación en Tu-85. Informe de Práctica profesional. Departamento de Antropología, Universidad de Chile, Santiago.

Cartajena, I., L. Núñez y M. Grosjean 2007. Camelid domestication in the western slope of the Puna de Atacama, Northern Chile. Anthropozoologica 42:155-173.

Eitel, B. y B. Mächtle 2009. Man and environment in the Eastern Atacama Desert (southern Perú): Holocene climate changes and their impact on pre-columbian cultures. En New Technologies for Archaeology: Multidisciplinary Investigations in Palpa and Nasca, Peru, editado por M. Reindel y G.A. Wagner, pp. 17-37. Natural Science in Archaeology, Springer, Berlin, Heidelberg. 
Faegri, K. y J. Iversen 1989. Textbook of Pollen Analysis. Cuarta edición. John Wiley and Sons, Chichester.

Gayó, E.M., C. Latorre, C.M. Santoro, A. Maldonado y R. De Pol-Holz 2012. Hydroclimate variability in the low-elevation Atacama Desert over the last 2500 yr. Clim. Past 8:287-306.

Grimm, E.C. 1987. Coniss a fortran 77 program for stratigraphically constrained cluster analysis by the method of incremental sum of squares. Computers and Geociences:13-35.

Grosjean, M. y L. Núñez 1994. Late glacial, early and middle Holocene environment, human occupation and resource use in the Atacama (Northern Chile). Geoarchaeology 9:271-286.

Grosjean, M., L. Núñez e I. Cartajena 1997. Mid-Holocene climate and culture change in the Atacama Desert, Northern Chile. Quaternary Research 48:239-246.

Grosjean, M., J. Leeuwe, W.O. van der Knaap, B. Ammann, W. Tanner, B. Messerli, L. Núñez, B. Valero-Garcés y H. Veit 2001. A $22,000{ }^{14} \mathrm{C}$ years B.P. sediment and pollen record of climate change of Laguna Miscanti $\left(23^{\circ} \mathrm{S}\right)$, Northern Chile. Global and Planetary Change 28:35-51.

Grosjean, M., I. Cartajena, M.A., Geyh y L.A. Núñez 2003. From proxy-data to paleoclimate interpretation: The mid-Holocene paradox of the Atacama Desert, northern Chile. Palaeogeography, Palaeoclimatology, Palaeoecology 194:247-258.

Heusser, C.J. 1990. Ice age vegetation and climate of subtropical Chile. Palaeogeography, Palaeoclimatology, Palaeoecology 80:107-127.

Holden, T. 1991. Evidence of prehistoric diet from Northern Chile: coprolites, gut content and flotation samples from the Tulán quebrada. World Archaeology 22:321-331.

Houston, J. y A.J. Hartley 2003. The central Andean westslope rainshadow and its potential contribution to the origin of hyper-aridity in the Atacama Desert. International Journal of Climatology 23:1453-1464.

Kuentz, A., A. Galán de Mera, M.P. Ledru y J.C. Thoure 2007. Phytogeographical data and modern pollen rain of the puna belt in southern Peru (Nevado Coropuna, Western Cordillera). Journal of Biogeography 34:1762-1776.

Latorre, C., J.L. Betancourt, K.A. Rylander y J. Quade 2002. Vegetation invasions into absolute desert: A $45.000 \mathrm{yr}$. rodent midden record from the Calama-Salar de Atacama basins, northern Chile (Lat. $22^{\circ}-24^{\circ}$ ). Geological Society of American Bulletin 114:349-366.

Latorre, C., J.L. Betancourt, K.A. Rylander, J. Quade y O. Matthei 2003. A vegetation history from the arid prepuna of northern Chile (22 $23^{\prime}$ 'S) over the last 13,500 years. Palaeogeography, Palaeoclimatology, Palaeoecology 194:223-246.

Latorre, C., J.L. Betancourt y M.T.K. Arroyo 2006. Late Quaternary vegetation and climate history of a perennial river canyon in the Río Salado basin $\left(22^{\circ} \mathrm{S}\right)$ of Northern Chile. Quaternary Research 65:450-466.

Latorre, C., J.L. Betancourt, J.A. Rech, J. Quade, C. Holmgren, C. Placzek, A.J.C. Maldonado, M. Vuille y K. Rylander 2005. Late Quaternary history of the Atacama Desert. En $23^{\circ} S$ : The Archaeology and Environmental History of the Southern Deserts, editado por M. Smith y P. Hesse, pp. 73-90. National Museum of Australia Press, Canberra.
López, P., I. Cartagena y L. Núñez 2013. Análisis de isótopos estables en colágeno de huesos de camélidos de quebrada Tulán, puna de Atacama, periodo Formativo Temprano (ca. 3.1002.400 a.p.). Chungara Revista de Antropología Chilena 45:237-247.

Luebert, F. y R. Pliscoff 2006. Sinopsis Bioclimática y Vegetacional de Chile. Editorial Universitaria, Santiago.

Maldonado, A., J.L. Betancourt, C. Latorre y C. Villagrán 2005. Pollen analyses from a 50000 -yr rodent midden series in the southern Atacama Desert (25 30' S). Journal of Quaternary Science 20:493-507.

Marquet, P.A., F. Bozinovic, G.A. Bradshaw, C. Cornelius, H. González, J.R. Gutiérrez, E. Hajek, J.A. Lagos, F. LópezCortez, L. Núñez, E.F. Rosello, C. Santoro, H. Samaniego, V.G. Standen, J.C. Torres-Mura y F.M. Jaksic 1998. Ecosistemas del Desierto de Atacama y área andina adyacente. Revista Chilena de Historia Natural 71:593-617.

McRostie, V. 2007. La Transición Arcaico-Formativa en la Quebrada de Tulán, Sur del Salar de Atacama, Chile. Evidencias Arqueobotánicas. Memoria de Título profesional de Arqueólogo, Departamento de Antropología, Universidad de Chile.

Messerli, B., M. Grosjean, T. Hofer, L. Núñez y C. Pfister 2000. From nature-dominated to human-dominated environmental changes. Quaternary Sciences Reviews 19:459-479.

Moreno, P.I., C. Villagrán, P.A. Marquet y L.G. Marshall 1994. Quaternary paleobiogeography of northern and central Chile. Revista Chilena de Historia Natural 67:487-502.

Núñez, L. 1995. Evolución de la ocupación y organización del espacio atacameño. En Agua, Ocupación del Espacio y Economía Campesina en la Región Atacameña, editado por P. Pourrut y L. Núñez, pp. 18-60. ORSTROM-Universidad Católica del Norte, Antofagasta.

- _ _ 1999. Fase Tilocalar: nuevas evidencias formativas en la Puna de Atacama (norte de Chile). En Formativo Sudamericano: una Reevaluación, editado por P. Ledergerber-Crespo, pp. 227242. Abya-Yala, Quito.

Núñez, L., I. Cartajena, P. de Souza, C. Carrasco y M. Grosjean 2006. Emergencia de comunidades pastoralistas formativas en el sudeste de la Puna de Atacama. Estudios Atacameños 32:93-117.

_. _ _ 2007. Quebrada Tulán: evidencias de interacción circumpuneña durante el Formativo Temprano en el sureste de la cuenca de Atacama. En Producción y Circulación Prehispánicas de Bienes en el Sur Andino, editado por A. Nielsen, M.C. Rivolta, V. Seldes y H. Mercolli, pp. 287-303. Colección Historia Social Precolombina 2, Editorial Brujas, Córdoba.

Núñez, L., M. Grosjean e I. Cartajena 1999. Un ecorrefugio oportunístico en la Puna de Atacama durante eventos áridos del Holoceno Medio. Estudios Atacameños 17:125:174.

_ _ _ _ 2001. Human dimensions of late Pleistocene/Holocene arid events in southern South America. En Interhemisferic Climate Linkages, editado por V. Markgraf, pp. 105-117. Academic Press, New York.

_ _ _ 2002. Human occupations and climate change in the Puna de Atacama, Chile. Science 298:821-824.

2005. Ocupaciones Humanas y Paleoambientes en la Puna de Atacama. Taraxacum, Universidad Católica del Norte, San Pedro de Atacama. 
- _ - 2010. Sequential analysis of human occupation patterns and resource use in the Atacama Desert. Chungara Revista de Antropología Chilena 42:363-391.

Núñez, L., M. Grosjean, B. Messerli y H. Schreier 1997. Cambios ambientales holocénicos en la puna de Atacama y sus implicancias paleoclimáticas. Estudios Atacameños 12:31-40.

Núñez, L., V. McRostie e I. Cartajena 2009. Consideraciones sobre la recolección vegetal y la horticultura durante el Formativo Temprano en el sureste de la cuenca de Atacama. Darwiniana 47:56-75.

Núñez, L. y R. Lorca 2009. Excavaciones en TU-85/Montículo Test 1: Cuadrículas D7 y C7. Informe de Avance, Proyecto Fondecyt 1070040 (Manuscrito en posesión de los autores).

Núñez, L. y C.M. Santoro 2011. El tránsito Arcaico-Formativo en la circumpuna y valles occidentales del Centro Sur Andino: hacia los cambios "neolíticos". Chungara Revista de Antropología Chilena 43:487-530.
Núñez, M. 2000. Movimientos y Voces en Peine. Tesis para optar al grado de Licenciada en Antropología y al Título de Antropóloga. Universidad Academia de Humanismo Cristiano, Escuela de Antropología, Santiago.

Paredes, A. Levantamiento topográfico de sitio Tulán-85. Informe de Avance Proyecto 2009 Fondecyt 1070040 (Manuscrito en posesión de los autores).

Rundel, P.W., M.O. Dillon, B. Palma, H.A. Mooney, S.L. Guilmon y J.R. Ehleringer 1991. The phytogeography and ecology of the coastal Atacama and Peruvian deserts. ALISO 13:1-49.

Stockmarr, J. 1971. Tablets with spores used in absolute pollen analysis. Pollen et Spores 13:615-621.

Wilke, H. 2012. Informe sobre sedimentos arqueológicos registrados en el sitio Tulán-85 (salar de Atacama). Departamento de Geología, Universidad Católica del Norte, Antofagasta. (Manuscrito en posesión de los autores). 


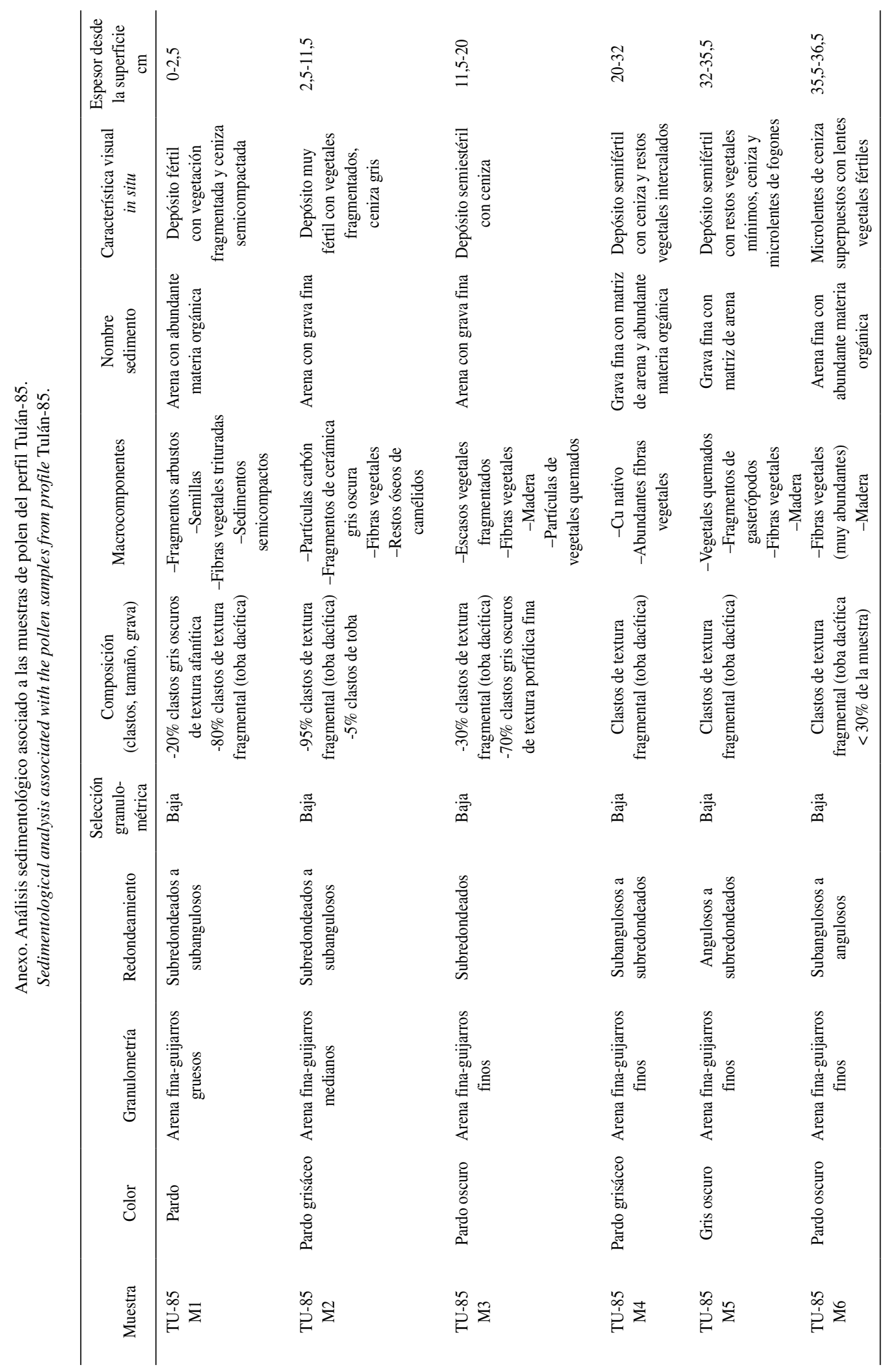




\begin{tabular}{|c|c|c|c|c|c|c|c|c|c|c|c|}
\hline 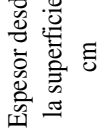 & $\begin{array}{l}\infty \\
0 \\
0 \\
n \\
0 \\
n \\
n\end{array}$ & $\begin{array}{l}\frac{\infty}{0} \\
0 \\
0\end{array}$ & $\begin{array}{l}\vec{\infty} \\
\dot{0} \\
\infty\end{array}$ & $\begin{array}{l}\infty \\
\frac{\infty}{\infty} \\
\infty\end{array}$ & $\begin{array}{l}\bar{i} \\
\frac{1}{\infty}\end{array}$ & $\frac{a}{a}$ & $\stackrel{\infty}{\rightrightarrows}$ & $\begin{array}{l}\stackrel{\Delta}{\Xi} \\
\stackrel{0}{\Xi}\end{array}$ & $\begin{array}{l}8 \\
\frac{8}{1} \\
\frac{1}{1}\end{array}$ & $\begin{array}{l}\infty \\
\frac{\infty}{0} \\
\underline{0}\end{array}$ & 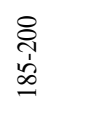 \\
\hline 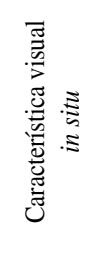 & 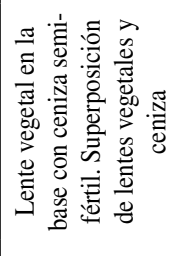 & 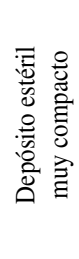 &  & 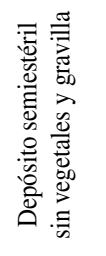 & 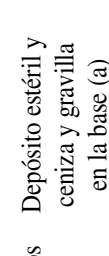 & 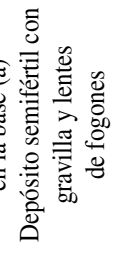 & 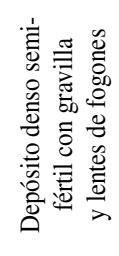 & 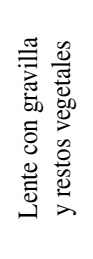 &  & 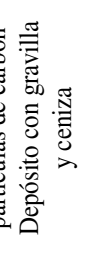 & 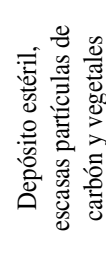 \\
\hline 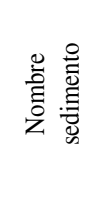 &  & 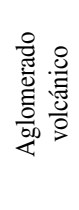 &  & 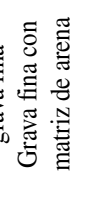 &  & 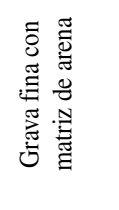 & 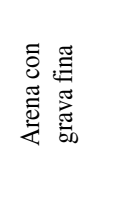 & 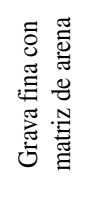 &  & 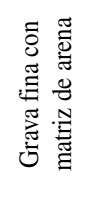 & 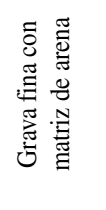 \\
\hline 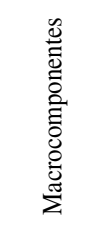 & 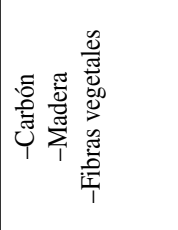 & z & 总 &  & 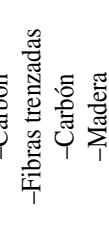 &  & 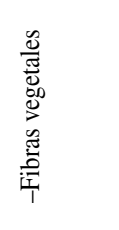 & 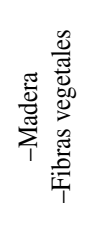 & 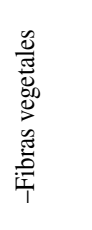 &  & z \\
\hline 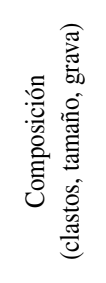 &  & 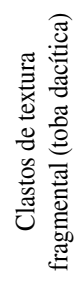 & 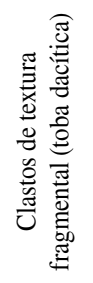 & 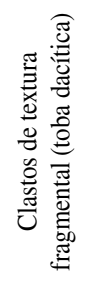 &  &  & 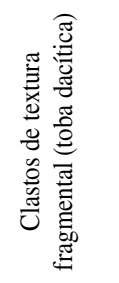 & 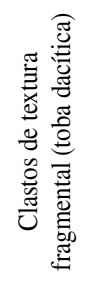 & 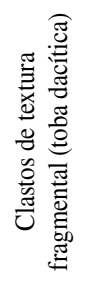 & 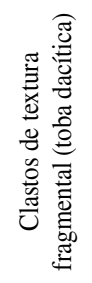 & 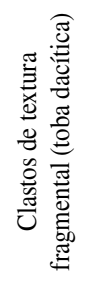 \\
\hline 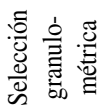 & 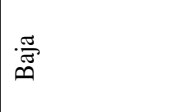 & 愛 & : & : & 泶 & 璦 & 菏 & 䨔 & 妥 & 璦 & 緎 \\
\hline 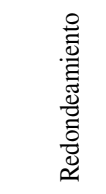 &  & 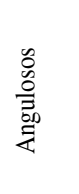 & 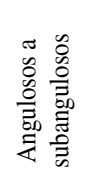 & 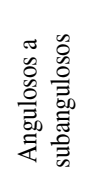 & 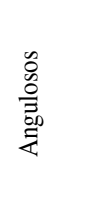 & 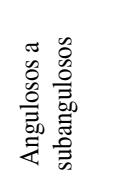 & 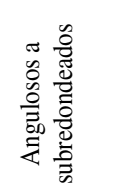 & 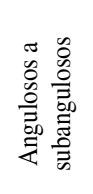 & 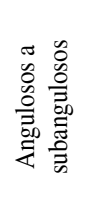 & 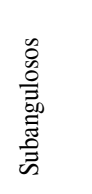 & 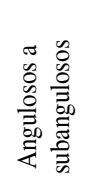 \\
\hline  &  &  &  & 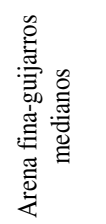 & 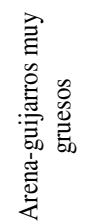 & 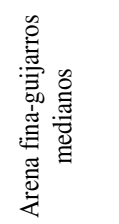 & 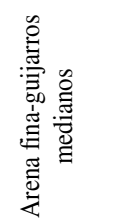 & 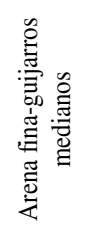 &  & 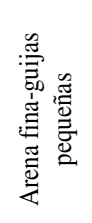 & 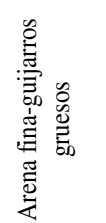 \\
\hline$\frac{\overline{0}}{0}$ & 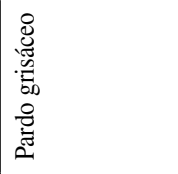 & 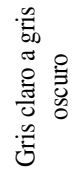 & 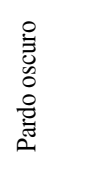 & 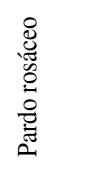 &  & 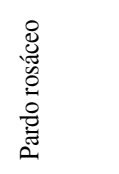 & 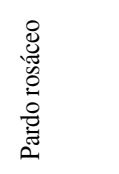 & 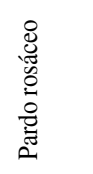 & 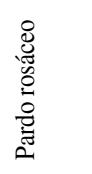 & 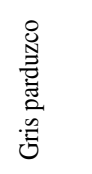 & 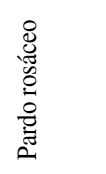 \\
\hline 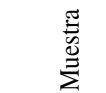 & 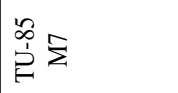 & $\stackrel{\infty}{i}^{\infty} \sum^{\infty}$ & 㤎 & 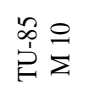 & 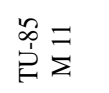 & 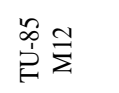 &  & 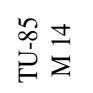 &  & 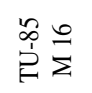 & 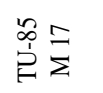 \\
\hline
\end{tabular}

